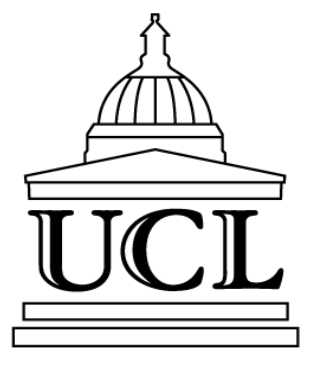

CENTRE FOR THE STUDY OF ECONOMIC \& SOCIAL CHANGE IN EUROPE

SCHOOL OF SLAVONIC \& EAST EUROPEAN STUDIES

\title{
A TWO-TIER OR MULTI-TIER EUROPE: ASSESSING THE INNOVATION CAPACITIES OF CENTRAL AND EAST EUROPEAN COUNTRIES IN THE ENLARGED EU
}

Slavo Radosevic

Working Paper No. 31

May 2003

ISSN 1476-1734

University College London Centre for the Study of Economic and Social Change in Europe Senate House, Malet Street, London, WC1E 7HU Tel: 44(020) 78638517 Fax :44(020) 78628641

Email: csesce@ssees.ac.uk 


\title{
A TWO-TIER OR MULTI-TIER EUROPE:
}

\section{ASSESSING THE INNOVATION CAPACITIES OF CENTRAL AND EAST EUROPEAN COUNTRIES IN THE ENLARGED EU}

\author{
Slavo Radosevic ${ }^{1}$
}

Summary: ${ }^{2}$

This paper assesses the innovation capacities of the central and east European (CEE) candidate countries and the countries of the EU using a set of 25 indicators organized within the national innovation capacity (NIC) framework. Based on regression and cluster analysis the paper shows that NIC in the enlarged EU does not follow a simple 'East - West' divide. The wider Europe is structured into three groups of countries and CEE countries are fall into two, the less developed and medium developed EU, groups. NICs in the enlarged EU are assessed across four dimensions of capacity: absorptive, $\mathrm{R} \& \mathrm{D}$, diffusion and demand. In each of these dimensions we observe a two- or threetiering of countries, which goes beyond a simple 'East' - ' West' pattern. The results of this assessment have important implications for candidate countries as well as for the EU policy towards structural assistance.

\footnotetext{
${ }^{1}$ Reader, University College London, School of Slavonic and East European Studies, Email: s.radosevic@ssees.ac.uk

${ }^{2}$ This paper was prepared within the EU Framework Programme V funded project: 'EU Integration and the Prospects for Catch-Up Development in CEECs: the Determinants of the Productivity Gap'. I am grateful to project participants and Hugo Hollander for useful comments on an earlier version of this paper.
} 


\title{
A TWO-TIER OR MULTI-TIER EUROPE: ASSESSING THE INNOVATION CAPACITIES OF CENTRAL AND EAST EUROPEAN COUNTRIES IN THE ENLARGED EU
}

\author{
Slavo Radosevic ${ }^{3}$
}

\section{INTRODUCTION}

With the progress in institutional transformation of central and east European countries (CEECs) transition issues have become secondary to growth, structural change and employment. The pre-accession activities of CEE candidate countries have further highlighted competitiveness issues and the capability of these economies to withstand the competitive pressures of the Single Market. Underpinning these concerns are concerns about productivity, technical change, innovation and R\&D in CEECs. Analysis of R\&D activities in CEECs suggests that sources of growth in these countries during the 1990s have not been directly linked to these activities (Radosevic and Auriol, 1999). Growth during the 1990s seems to be better explained as the outcome of a combination of initial conditions and reform policies rather than by growth determinants related to capital and technology accumulation (see Campos and Corriceli, 2002 for an overview). The technological upgrading that has taken place has not been linked to the R\&D system but rather to the acquisition of knowledge in the production process and through different forms of firm based learning (Dyker and Radosevic, 1999).

Further continuous and high growth is essential if CEECs are to resolve an accumulation of social and environmental problems, to increase standards of living and to improve social and economic cohesion within the enlarged EU, all of which will require continuous increases in productivity, which are unlikely to materialize without technology accumulation and the building of a knowledge-based economy. Given their income levels, the CEECs have still relatively large numbers of research scientist and engineers (RSE) and many have a favourable education structure. Both these factors should, according to new growth theory, produce much more robust growth than was observed during the 1990s. Yet, recovery of the CEECs during the 1990s was unrelated to their R\&D. ${ }^{4}$

The failure of the majority of the CEECs to grow according to expectations is usually attributed in part to differences among countries in their reform process, i.e. transition process. However, during the last 10 years these economies have established market economy institutions and most have achieved the EU designation of a

\footnotetext{
${ }^{3}$ Reader, University College London, School of Slavonic and East European Studies, Email: s.radosevic@ssees.ac.uk

${ }^{4}$ Simple correlation coefficients between growth of GDP and share of GERD/GDP for 1992-1999 period are negative for six out of nine CEE economies.
} 
'functioning market economy'. However, this by itself does not automatically mean there will be an increase in productivity and that growth will occur.

Growth is a complex and highly idiosyncratic process based on a particular interaction between incentives, institutions and capabilities. In an increasingly integrated world economy, growth differences increasingly seem to be rooted in micro rather than macro-economic differences, and to depend on a variety of dimensions such as technology, public institutions, etc (Porter, 1990). There is a general consensus among economists that technological innovation plays a central role in the process of long-run economic growth. However, there are a wide variety of approaches when it comes to understanding the underlying drivers of growth and the innovation process itself. Innovation studies show that innovation does not result solely from the supply of R\&D (see Freeman and Soete, 1997 for an overview). The exclusive focus in new growth theory on 'knowledge stocks' and on the pool of R\&D labour is far from being sufficient to understand what is the potential of the CEE for growth based on R\&D and innovation. In order to understand the key issues behind country differences in growth and technology we have to organize an analysis within a multi-dimensional framework, i.e. one that captures several important dimensions - all of which determine innovation capacity.

In this paper we try to assess the R\&D and innovation capacity of the CEECs within a systems of innovation framework using a set of 25 quantitative indicators organized within the national innovation capacity (NIC) framework. We try to answer three particular questions. First, whether levels of productivity of the CEE/EU countries are dependent on NIC and its components? Second, what are the levels of NICs in CEECs compared to the EU? Third, what are the specific strengths and weaknesses of the CEECs' innovation capacities?

The paper is organized in five sections. In the next section, we review the different approaches that have been used to analyze relationships between productivity, R\&D and innovation and explain the elements of the national innovation capacity (NIC) framework. Section three describes the data sources and methodology. Section four presents the results of the analysis and section five discusses these results and outlines some policy implications deriving from the analysis.

\section{PRODUCTIVITY, R\&D AND INNOVATION: COMPETING FRAMEWORKS}

The ultimate measure of the competitiveness and growth of an economy is its productivity (Porter, 1990). Intuitively we know that growth in productivity should be linked to technology. However, economists find it difficult to show how technology affects productivity and then growth.

The neo-classical theory of growth (Solow, Swain) does not consider sources of technology but simply assumes that technology effects are those that cannot be ascribed to growth of capital and population. Early growth accounting exercises, which are based on this approach, ascribed most growth to residual or multi-factor productivity. ${ }^{5}$

\footnotetext{
${ }^{5}$ Efficient allocation of resources is an alternative source of growth, which seems to play important role in technological innovation and technology diffusion as drivers of productivity growth. For example, Scarptea et al. (2002) quotes Haltiwanger $(1997,2000)$ who reports that for the United States manufacturing sector, roughly half of multi-factor productivity growth over the course of a decade can be accounted for by the re-
} 
However, improved measurements of capital and labour have shown that the rate of growth based on residual productivity has declined significantly.

Economists often tend to equate productivity growth with technology. Based on this assumption the measurement of technical change is reduced to the measurement of multi-factor productivity growth whereas, in reality, neither technology, nor technical change necessarily translates into productivity. For example, diffusion of information technology (IT) may not necessarily be reflected in productivity (cf. the so-called Solow paradox). Alternatively, productivity is not necessarily the result of technical change but may derive from economies of scale, cyclical effects or measurement errors. In addition, productivity indices tend to ascribe too much of growth to capital, and neglect the induced effect from previous growth driven by technology to the current contribution of capital (OECD, 2002, p. 112, 113). However, the major weakness in the total factor productivity (TFP) approach is that it is not appropriate to consider physical capital, human capital and technology as separate factors. Metaphorically speaking, the TFP approach assumes that the secret of producing a good cake lies in finding out its ingredients and their weights. However, historical evidence suggests that instead of an exclusive focus on 'stocks' we should give much more attention to interactions, composition and structures, i.e. 'flow' factors.

New growth theory has resolved, at least in modeling terms, the exogenous nature of technical progress of the Solow model where growth materializes through the imposition of a productivity parameter. Rather in contrast, new growth theory introduces some structural features like size of the R\&D sector or rate of obsolescence of new knowledge, which determine long-run growth (see Aghion and Howitt, 1998 for an overview).

Due to the specific nature of $R \& D$, which is a non-rival and partially excludable good, it is central to the production of knowledge. The theory assumes that there is an 'ideas generating sector' (R\&D) which, in interaction with demand for R\&D by innovators, generate innovations. Within this framework, 'ideas production' is determined by the number of workers devoted to 'ideas production' and the existing stock of ideas from which these workers can draw in their 'ideas production' work. By changing the number of researchers working in 'ideas production' and shifting the productivity of production of new ideas, technical change becomes endogenous.

The advantage of new growth theory is that it throws light on the process of R\&D supply and also in part on the process of absorption of R\&D results. In the context of

allocation of outputs and inputs away from less productive to more productive businesses (p. 116). However, we should bear in mind that it is difficult to separate reallocations (its sources and effects) from accumulated technology and innovation. This may be the reason why for the CEECs, the effect of relocations, does not seem to be strong. For Former Soviet Union countries, De Broeck and Koen (2000) show that the contribution of sectoral composition to changes in total factor productivity were positive in the early transition but their effect was small, indicating that sectoral input reallocations did not have a major impact on productivity (p. 20). In CEE the process of structural change has been very strong but the main sources of productivity growth were not sectoral reallocations but intra-sectoral reallocations. Research on six Central European countries shows that the sectoral content of the productivity gap with the EU is low and varies between 27.7\% in Slovakia to 5.3\% in Czech R (Stephan, 2002). Hence, most of the productivity gap derives from intra-sectoral differences or differences in technology, management and organisation. This result has also been confirmed by a large scale enterprise survey conducted by Carlin et al. (2001) who conclude that the major sources of productivity growth in transition economies are not interbut intra-sectoral reallocations. 
CEE, new growth theory can illuminate several issues. For example, the factors that affect the number of research scientists and engineers (RSEs) and demand for R\&D. How the obsolescence of R\&D knowledge from the past affects the current productivity of $\mathrm{R} \& \mathrm{D}$ sector. How the rigidity of intellectual property rights affects the generation of new ideas vs. their absorption or diffusion.

A recent exploration by Verspagen (2001) of the determinants of growth in the OECD countries suggests that the concerns of new growth theory are becoming increasingly relevant. Verspagen (2001) found that in the last 10 to 20 years R\&D has become a crucial part of the catching up strategy, i.e. R\&D is no longer associated only with the world technology frontier. Second, differences among countries in terms of 'pure' technology competitiveness (patents) are becoming more and more important in explaining growth differences.

At an aggregate level, R\&D expenditures tend to show a statistically significant relationship to productivity growth, but only explain a relatively small part of overall annual movements in multi-factor productivity. This indicates the presence of other factors (OECD, 2002, p. 113).

However, as pointed out by the EC (2002b) the supply of R\&D is only a part of the overall process of innovation that leads to a finished product being placed on the market or to economic growth at the national level. The degree of technology and knowledge flows across public and private sectors strongly affects the impact of technology on the economy (OECD, 2002b). So, if we want to understand the effects of $\mathrm{R} \& \mathrm{D}$ and innovation on productivity we must look beyond the R\&D sector to the diffusion of knowledge and new technologies.

R\&D spillovers, transfer and diffusion are not automatic. Innovation studies have recognized the complex web of relationships that exist between the R\&D system and innovation and growth (Freeman and Soete, 1997; Perez, 2002). The complexity arises from the institutional context in which innovative firms operate (Nelson, 1993; Lundvall, 1992, Edquist, 1999). The effectiveness of the innovation process may be affected by the quality of the organizational structures and networks in the economy (von Tunzelmann, 1995; Porter, 1990). All this points to the importance of national systems of innovation and, in an increasingly integrated world economy, of local systems of innovation. For example, the evidence suggests that international knowledge spillovers tend to be smaller than domestic spillovers, which demonstrates the importance of national non-market linkages for growth (Sanghoon and Hemmings, 2000, p.21).

Within this approach the competitiveness and productivity of an economy means much more than high market share or efficient and low cost firms (Porter et al., 2002). Externalities and network linkages between firms and sectors are producing outcomes that are difficult to explain by aggregate variables. Approaches based on aggregate variables are uni-dimensional and thus run contra to the multi-level and multidimensional nature of growth and technical change. Overly aggregate approaches, which, for example, measure contributions of different factors like R\&D to productivity growth (to paraphrase Grilliches, 1997), only shift the problem to a new set of questions. Whether or not there was investment in R\&D and where do improvements in contribution of R\&D come from?

On the other hand, overly disaggregated approaches to understanding the underlying causes of growth, innovation and productivity change, which are usually 
institutional, historical, and case study approaches, often have limitations in terms of their generality and wider relevance.

Obviously, these different approaches have to be complemented. In this case, we pursue an intermediate line by employing a large number of indicators within a system of innovation framework (Lundvall, 1992; Nelson, 1993; Edquist, 1997). The increasing availability of data has made this approach very popular, in particular because of its use of composite indicators based on a large amount of data that measure different components of growth, technology and competitiveness. Examples are Porter and colleagues' approach to calculating Current Competitiveness and the Growth Competitiveness indexes (Porter et al., 2002), the EU Innovation Scoreboard EC (2001; 2002), the EU Enterprise Scoreboard (CEC, 2000), the UNDP (2002) measurement of human development index, and UNIDO's (2002) competitive industrial performance index. All these approaches combine a variety of different indicators, which should be able to capture different dimensions of the phenomena and aggregate them into composite indicator.

The most problematic stage in this approach is aggregation. In calculating their Current Competitiveness Index Porter et al. (2002) combine the individual micro dimensions of competitiveness using common factor analysis to provide a single composite proxy of the relative microeconomic competitiveness of each country. The Growth Competitiveness Index is a composite measure of the quality of public institutions, the macroeconomic environment and technology, with each of these elements weighted depending whether they relate to technologically advanced (core innovators) or follower (non-core) countries. Each of these components is a combination of several subindexes. For example, the technology index for non-core economies comprises $1 / 8$ of the innovation subindex $+3 / 8$ technology transfer subindex $+1 / 2$ ICT subindex. Each of these subindexes is in turn a combination of hard and soft (survey based) data.

When calculating the competitiveness of transition economies Zinnes, Eilat and Sachs (2001) use seven subindicators (openness, technology, good government, infrastructure, the financial sector, labour market and institutions). With the exception of technology, labour and infrastructure indicators, because of the smaller availability of data, they are given equal weights. They defend the use of prior weights rather than weights derived through factor or principal component analysis by arguing that 'all economic variables are inherently conceptual, artificial constructs defined only in terms of their data definitions' (p. 323).

UNIDO's (2002) Competitive Industrial Performance Index is a simple average of the four standardized basic indicators with no weights assigned (Manufacturing value added per capita, Manufactured exports per capita, Share of medium and high-tech activities and Share of medium and high tech products in manufactured exports).

Similarly, Campos (2000) measures the impact of institutions on growth in 25 transition economies by using four indicators for different institutional dimensions of 'governance' and aggregating them by simple averaging. Each of the four indicators is constructed based on an aggregation of several other indicators.

Aggregation has the advantage that it summarizes large sets of dimensions into one number This allows countries to be ranked and causes of differences to be sought in individual indexes and subindexes. However, the more complex the composite indicator 
the less useful it is as a learning and analytical tool for understanding reality and drawing policy implications. For example, the EU innovation scoreboard is moderately useful in its aggregate form, but its individual indicators grouped into four groups (human capital, knowledge generation, knowledge diffusion, output and markets) can be very revealing.

A second problem, which is not unique to this methodological approach, is the conversion of theoretical concepts or frameworks into specific indicators. For example, Ziness, Eilat and Sachs (2001) adopt as a technology index the number of fax machines per 100 persons, vehicles per 1000 persons and Internet hosts per capita giving them the respective weights of $0.2,0.2$ and 0.6 . Elsewhere, identical indicators are used to denote either supply or demand aspects.

In a nutshell, the value of this approach rests on its conceptual framework, which organizes different indicators. If the conceptual framework is robust, theoretically and empirically, and if individual components represent individual, preferably, hard data then this approach can be relevant, both from an academic and from a policy perspective.

In what follows, similar to Porter et al. (2002), and EC (2002; 2001), we look beyond R\&D to understand innovation capacity. Following the national innovation system approach we organize the indicators into four groups (R\&D supply, absorptive capacity, diffusion and demand). Growth and innovation capacity of an economy depend not only on the supply of R\&D but also on the capability to absorb and diffuse technology and on the demand for its generation and utilization. Figure 1 graphically presents four elements of the innovation capacity conceptual framework. Individual elements of the framework are interrelated and, in aggregation, they produce the national innovation capacity.

\section{National innovation capacity framework}

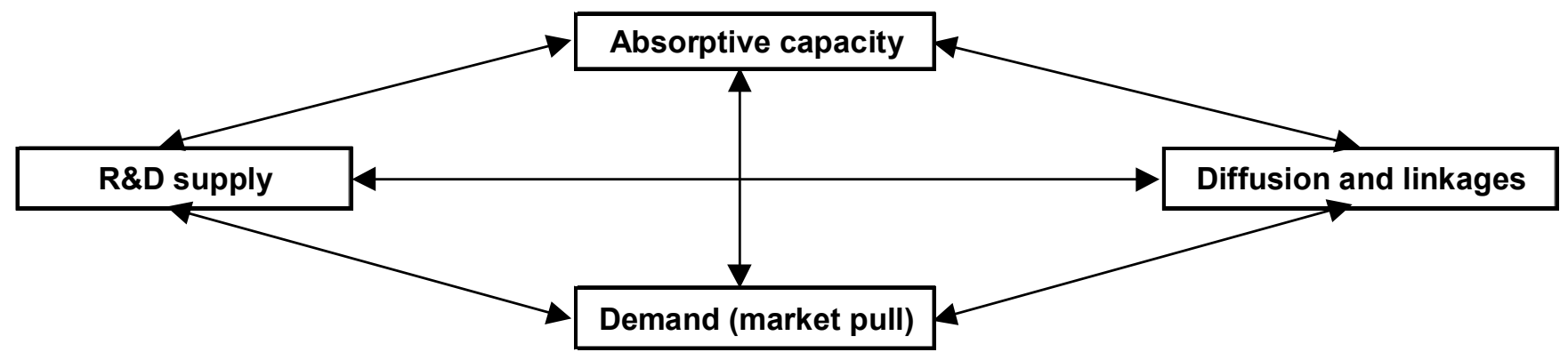

Absorptive capacity is the ability to absorb new knowledge and adapt imported technologies (Cohen and Levinthal, 1989). This capability is essential if catching-up economies are to grow and innovate. R\&D capability is important not only to generate new knowledge but also as a mechanism to absorb it (Cohen and Levinthal, 1990). Diffusion is the key mechanism for reaping economic benefits from investment in $R \& D$ and for increasing absorptive capacities (Davies, 1979). Demand for R\&D and innovation is the key economic mechanism that initiates wealth generation processes in $R \& D$, absorption and diffusion activities (Easterly, 2002). 
This conceptual framework does not differ substantially from the approaches already mentioned. It builds on the results of innovation and competitiveness studies. However, we believe that its simplicity, variables which proxy individual elements together with their availability, make this approach robust and relevant, both academically and in policy terms.

\section{DATA SOURCES AND METHODOLOGY}

The analysis is based on a series of 25 indicators compiled for $10 \mathrm{CEE}$ candidate countries and 14 EU countries. These data are classified into the four groups of the NIC framework (see figure 1 and table 1).

Two criteria were used in the selection of indicators; first, relevance to the analysis and, second, availability.

Indicators of absorptive capacity are human capital indicators related to education and lifelong learning combined with the share of employment in medium-high tech industries and services. The first four indicators describe the education and learning aspects of absorptive capacity. Employment in medium-high tech industries and services indicate the potential for catch up, which is easier if economies are specialized in technology intensive sectors.

Indicators of $R \& D$ supply include $R \& D$ expenditures, personnel and three types of patent outputs. ${ }^{6}$ Indicators of diffusion include the share of enterprises that undertake training, the costs of vocational training in the labour costs of all enterprises, ISO9000 standards per capita, PC and Internet per capita and share of the ICT market in GDP.

Demand is proxied by three groups of indicators: finance, competition and macroeconomic stability. The share of the stock market in GDP and the share of domestic credit provided by the banking sector proxy the level of development of the financial system. We assume that the more developed the financial system the better it can articulate demand for innovation, given equality of technological opportunities. Share of trade and foreign direct investments (FDI) in GDP are used as proxies for the intensity of competition together with the index of patent rights. Usually, FDI are taken as a proxy for supply of capital and technology. However, in the case of CEE they primarily act as agents that radically change the domestic market and industry structure with competition enhancing but also competition reducing effects. In all CEECs, with the possible exception of Hungary, FDI are dominantly market-seeking which means that their competition effects are pronounced. However, competition does not affect productivity and innovation in a direct and easily measurable way.

The index of patent rights is constructed by Ginarte and Park (1996). The G-P index is constructed as a scoreboard of five features of patent protection: (1) extent of coverage; (2) membership in international patent agreements; (3) provisions for loss of

\footnotetext{
${ }^{6}$ Elsewhere (for example, EC, 2002b), patents are used as proxy for demand for R\&D. By taking patents as a proxy for demand we assume that the supply of knowledge and finance is unlimited and that only incentives (intensity of protection rights) and technological opportunities determine the demand for new technology. We consider that for our purposes this is a rather heroic assumption and we use patents as proxy for R\&D supply. As one of seven variables on the demand side, we use the index of patent rights constructed by Ginarte and Pack (1997).
} 
protection; (4) enforcement mechanism; and (5) duration of protection. Each of these categories is broken into several sub-components and weighted in such a way that each category ranges in value from 0 to 1 . These categories are summed as unweighted components so the index value ranges from zero to five. Higher values of the index indicate stronger levels of protection. ${ }^{7}$ However, the index does not show the degree to which intellectual property rights (IPR) laws are enforced and IPRs are actually implemented, which should be taken into consideration when interpreting data. Smarzynska (2002) has developed an index that takes into account the actual degree of implementation of IPRs and that index is used here.

Unemployment and consumer price indexes indicate the degree of macroeconomic stability. We assume that macroeconomic stability through extending the horizon for entrepreneurs promotes demand for innovation.

Compiling 25 variables for 24 countries should result in 350 observations.

However, 18 observations or $5 \%$ of the data set are not available. We estimated missing data by regression estimates ${ }^{8}$. Due to the large proportion of missing data for Luxembourg and the possible bias of estimates we excluded it from the analysis.

Table 1: Data and sources

\section{Indicator}

\section{Absorptive capacity}

1 Expenditures in education in \% of GDP

2 S\&E graduates (\%o 20-29 population)

3 Population with 3rd level education

4 Participation in life-long learning (\% of working age pop)

5 Employment medium/high-tech manufacturing

6 Employment high-tech services

\section{R\&D supply}

1 Public R\&D expenditures. (\% GDP)

2 Business R\&D expenditures (\% GDP)

3 R\&D personnel per labour force

$4 \quad$ EPO high-tech patents (per mln pop)

$5 \quad$ USPTO high-tech patens (per mln pop)

6 Resident patents per capita

\section{Diffusion}

1 training enterprises as \% of all enterprises

2 CVT in \% of labour costs of all enterprises

3 ISO 900 certifications per per capita

$4 \quad$ Internet users per 10,000 inhabitants 2001

$5 \quad$ PC per 100 inhabitants 2001

6 ICT expenditures (\% GDP)

\begin{tabular}{|c|c|c|}
\hline Abbreviation & Year & Source \\
\hline eductgdp & 1999 & Eurostat \\
\hline segrdpop & 1999 & Trendchart $^{9}$ \\
\hline pop3educ & 2001 & Trendchart \\
\hline 1learng & 2001 & Trendchart \\
\hline emplmdhtc & 1999 & Trendchart \\
\hline emphsrvc & 1999 & Trendchart \\
\hline pubrd & 2000 & Trendchart \\
\hline besrd & 2000 & Trendchart \\
\hline rdpsnlab & 2000 & Eurostat \\
\hline epopc & 2000 & Trendchart \\
\hline usptopc & 2000 & USPTO \\
\hline respat & 2000 & WIPO \\
\hline
\end{tabular}

trainent $\quad 2000$

cvtlabct $\quad 2000$

iso9kpc 2000

internet $\quad 2000$

ppcpc 2000

ictgdp $\quad 2000$

Eurostat
Eurostat
ISO
ITU
ITU
Trendchart

\footnotetext{
${ }^{7}$ For a full description of the methodology, see Ginarte and Park (1996).

${ }^{8}$ We estimate missing data for cvtlabct, trainent, and emplmdhtec based on ppcpc, for llearng based on cvtlabct, for fdigdp based on ictgdp, for segrdpop based on isk9pc, and for iprindex based on emplmdhtec. All estimates are highly significant and with expected signs.

${ }^{9} \mathrm{EC}(2002 \mathrm{a})$
} 


\section{Demand (Finance/Competition/Macroeconomic stability)}

$\begin{array}{llll}1 & \text { Stock market capitalisation in \% GDP } & \text { stockmkt } & 1999 \\ 2 & \text { Domestic credit provided by banking sector (\%GDP) } & \text { domcredi } & 1999 \\ 3 & \text { Share of FDI in GDP, 1999 } & \text { fdigdp } & 1999 \\ 4 & \text { Share of trade in GDP, 1999 } & \text { tradegdp } & 1999 \\ 5 & \text { Index of patent rights } & \text { iprindex } & 1999\end{array}$

$6 \quad$ Registered unemployment

7 Consumer price index

unempl 2000

cpi 2000
World Bank

World Bank

UNCTAD

World Bank

Ginarte and

Pack (1997)

and

Smarzynska

(2002)

UNECE

UNECE

Indicators of national innovation capacity from table 1 are used to calculate a summary innovation capacity index and its components (absorptive capacity, R\&D supply, diffusion capacity, and strength of demand for innovation). We follow a procedure based on that developed by Zinnes et al. (2001) and Porter et al. (2002). We standardize data, multiply them by assigned weights and add together all the resulting products. In this way, we construct aggregate values for each of the four components of national innovation capacity. By summing the values of four components we calculate the aggregate national innovation capacity index. We assign equal weights to all indicators except for a few cases where indicators measure similar aspects of components in which case we reduce the weight of individual indicators. For absorptive capacity each of six indicators carries one-sixth of the weight. For R\&D supply, we assign one-fifth to each of indicators since we treat US and European patent office patents as one indicator, but with a half weight assigned to each of them. We adopt the same procedure to calculate diffusion capacity. We assign one-fifth to each of five indicators since we treat Internet use and PCs per capita as one indicator with a half weight each. Unemployment and consumer price indexes are inversely proportional to the NIC index. We change the signs of these two indicators to make them, like other indicators, positively proportional. The summary innovation capacity index is the simple summation of four components.

The innovation capacity index and its components are than regressed on manufacturing labour productivity. Data on labour productivity are Eurostat data based taking the EU15 index as the average.

We also estimated weights of individual indicators based on factor analysis Correlation coefficient between ranking of countries based on factor analysis and based on simple weights as described above is 0.994 . In that respect, use of factor analysis does not provide different estimates. However, regression estimates of indexes based on factor analysis on labour productivity are somewhat less significant. Hence, we do not use these estimates in the paper.

We use the indicators from table 1 for a cluster analysis. We undertake two types of cluster analysis using SPSS10.0 and based on Hair et al. (1998). First, we use a hierarchical method to identify the appropriate number of clusters. Second, we use a nonhierarchical procedure based on number of clusters from the hierarchical analysis to check for consistency of clustering and robustness of results. Because our data are in 
metric form we use squared Euclidian distance based on standardized data. For hierarchical clustering we use Ward's agglomerative method to minimize the withincluster differentiation and to avoid problems in 'chaining' of observations. ${ }^{10}$ In the analysis based on a hierarchical method we use the 'stopping rule' in order to determine the appropriate number of clusters. The 'stopping rule' allows us to determine the appropriate number of clusters based on changes in agglomeration coefficients, which we report below. ${ }^{11}$ We controlled for the existence of outliers based on the agglomeration schedule and observing dendograms, but we did not have to delete either a country or a variable to achieve this.

In the second stage, based on the number of clusters derived from the hierarchical method, we profile clusters and report cluster membership and final cluster centres, and report the results of ANOVA for testing differences between clusters.

\section{RESULTS: R\&D, NATIONAL INNOVATION CAPACITY AND PRODUCTIVITY IN AN ENLARGED EUROPE}

In the remainder of this paper we assess, first, the innovation capacity of the CEECs based on indicators for all four elements of the NIC framework. Second, we test econometrically the relationship between the summary national innovation capacity index and manufacturing labour productivity as well as each of its components. Third, we use cluster analysis to find how the aggregate innovation capacity of the enlarged EU and its components is structured, i.e. whether 'East - West' or some other more complex divide will be the key feature of future EU patterns of technology upgrading and growth.

\subsection{Innovation capacities and their components}

National innovation capacity is a synthetic indicator comprising four components (absorptive capacity, R\&D capacity, diffusion and demand capacities). All four components are equally important for technological innovation. Figure 2 and the NIC column in table 2 rank CEE and EU countries based on summary NIC coefficients. These data show three features of innovation capacities in an enlarged EU.

\footnotetext{
${ }^{10}$ Ward's method calculates the sum of squares between two clusters summed over all variables.

${ }^{11}$ The agglomeration coefficient is the within cluster sum of squares. Small coefficients indicate that clusters are homogenous while a sudden jump in the value of the coefficients indicates that two very different clusters are merged.
} 
Figure 2: National innovation capacities

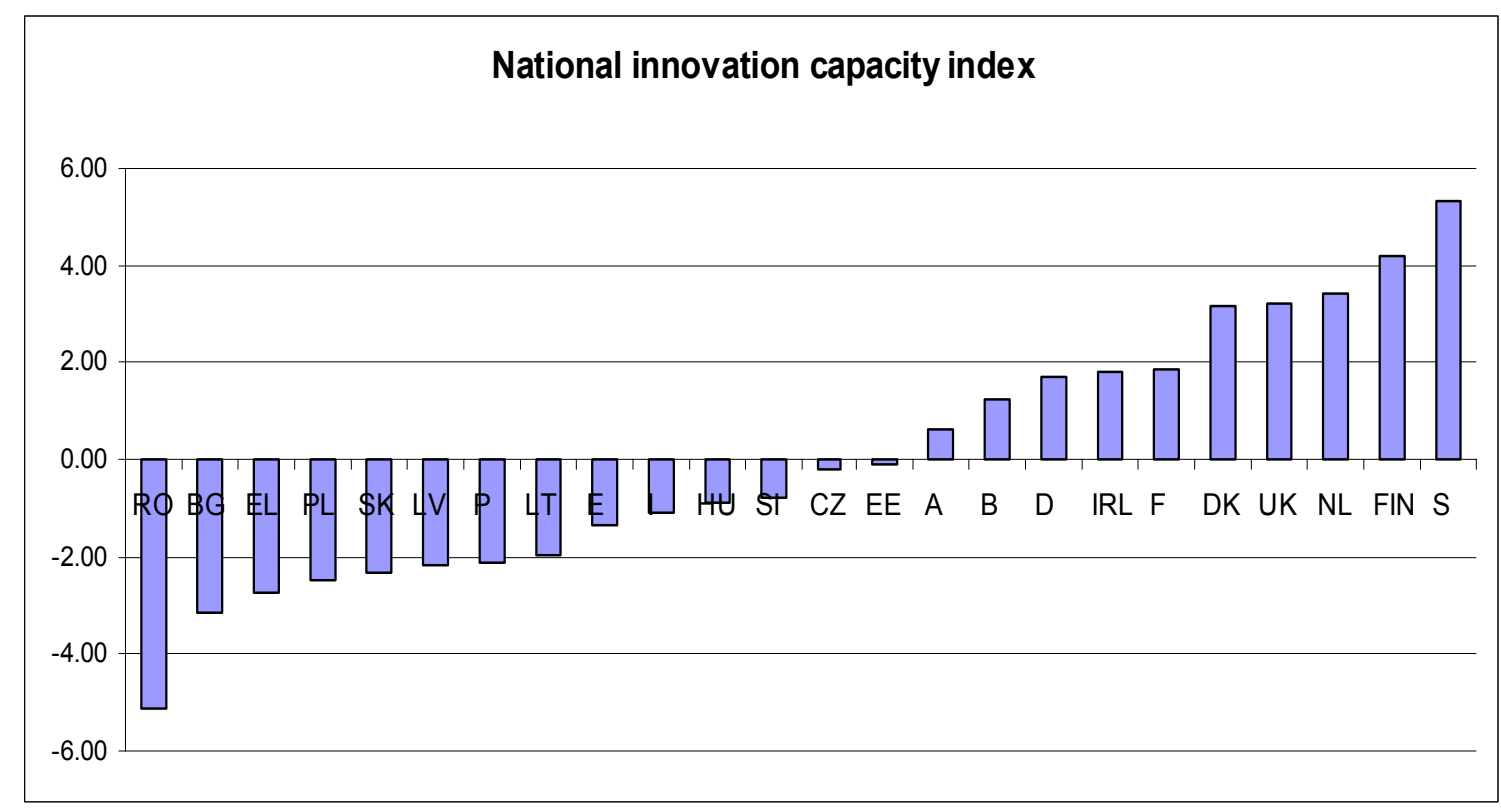

Table 2: Ranking by coefficients of national innovation capacity (NIC) and its components

\begin{tabular}{|c|c|c|c|c|c|c|c|c|c|c|}
\hline & \multicolumn{2}{|c|}{$\begin{array}{l}\text { Nat. Innov. } \\
\text { Capacity }\end{array}$} & \multicolumn{2}{|c|}{$\begin{array}{l}\text { Absorptive } \\
\text { capacities }\end{array}$} & \multicolumn{2}{|c|}{ R\&D capacities } & \multicolumn{2}{|c|}{\begin{tabular}{|l|} 
Diffusion \\
capacities
\end{tabular}} & \multicolumn{2}{|c|}{$\begin{array}{l}\text { Demand } \\
\text { capacities }\end{array}$} \\
\hline & RO & -5.14 & EL & -1.30 & RO & -1.06 & RO & -1.53 & RO & -1.47 \\
\hline 2 & $\overline{B G}$ & -3.15 & RO & -1.08 & $\mathbf{L V}$ & -0.88 & BG & -1.05 & BG & -0.85 \\
\hline 3 & $\overline{\mathrm{EL}}$ & -2.75 & $\mathrm{P}$ & -0.84 & SK & \begin{tabular}{|c|}
-0.73 \\
\end{tabular} & PL & -0.77 & SK & -0.84 \\
\hline 4 & $\mathbf{P L}$ & -2.49 & BG & -0.59 & BG & -0.67 & EL & -0.76 & PL & $\begin{array}{l}-0.65 \\
\end{array}$ \\
\hline & SK & -2.33 & PL & -0.44 & PL & -0.63 & LT & -0.75 & LV & -0.65 \\
\hline & $\mathbf{L V}$ & -2.19 & SK & -0.42 & $\mathrm{P}$ & -0.57 & $\mathrm{P}$ & -0.70 & LT & -0.59 \\
\hline 7 & $\mathrm{P}$ & -2.14 & I & -0.39 & LT & -0.56 & $\mathrm{E}$ & -0.55 & SI & -0.44 \\
\hline & LT & -1.95 & HU & -0.35 & EE & -0.54 & SI & -0.38 & EL & -0.22 \\
\hline 9 & $\mathrm{E}$ & -1.33 & $\mathbf{L V}$ & -0.32 & EL & -0.47 & LV & -0.35 & $\mathrm{E}$ & -0.11 \\
\hline 10 & & -1.11 & $\mathrm{E}$ & -0.24 & HU & -0.46 & SK & -0.33 & I & -0.08 \\
\hline 11 & HU & -0.88 & $\mathrm{~A}$ & -0.22 & $\mathrm{I}$ & -0.44 & $\mathrm{I}$ & -0.20 & $\mathbf{C Z}$ & -0.07 \\
\hline 12 & SI & -0.76 & $\mathbf{C Z}$ & -0.14 & E & -0.43 & HU & -0.11 & $\mathrm{P}$ & -0.03 \\
\hline 13 & $\mathbf{C Z}$ & -0.22 & LT & -0.04 & $\mathbf{C Z}$ & -0.32 & A & 0.13 & $\mathbf{H U}$ & 0.04 \\
\hline 14 & $\mathbf{E E}$ & -0.11 & \begin{tabular}{|l} 
SI \\
\end{tabular} & 0.02 & IRL & -0.26 & EE & 0.23 & $\mathbf{E E}$ & 0.12 \\
\hline 15 & A & 0.61 & $B$ & 0.04 & SI & 0.04 & B & 0.24 & $\mathrm{~F}$ & 0.17 \\
\hline 16 & $\mathrm{~B}$ & 1.23 & EE & 0.08 & B & 0.11 & $\mathrm{D}$ & 0.26 & FIN & 0.22 \\
\hline 17 & $\mathrm{D}$ & 1.71 & $\mathrm{D}$ & 0.24 & $\mathrm{~A}$ & 0.28 & $\mathbf{C Z}$ & 0.31 & DK & 0.27 \\
\hline 18 & IRL & 1.83 & NL & 0.26 & UK & 0.38 & $\mathrm{~F}$ & 0.34 & $\mathrm{D}$ & 0.29 \\
\hline 19 & & 1.86 & $\mathrm{~F}$ & 0.49 & $\mathrm{NL}$ & 0.59 & FIN & 0.65 & A & 0.43 \\
\hline 20 & DK & 3.16 & IRL & 0.59 & DK & 0.79 & IRL & \begin{tabular}{l|l}
0.72 \\
\end{tabular} & UK & 0.64 \\
\hline 21 & UK & 3.20 & UK & 0.98 & F & 0.86 & DK & 1.00 & IRL & 0.78 \\
\hline 22 & NL & 3.41 & DK & 1.10 & D & 0.92 & NL & 1.16 & S & 0.81 \\
\hline 23 & FIN & 4.20 & FIN & 1.29 & S & 2.00 & UK & 1.20 & $\mathrm{~B}$ & 0.84 \\
\hline 24 & & 5.35 & S & 1.29 & FIN & 2.03 & $\mathrm{~S}$ & 1.25 & NL & 1.40 \\
\hline
\end{tabular}


First, all CEECs are below the enlarged EU average NIC coefficient. In this respect, CEECs are clearly pushing the average NIC index downwards. In particular, the index is affected by Romania (-5.14) and Bulgaria (-3.15). The other seven CEECs do not deepen the innovation capacity gap within the enlarged EU but actually make the enlarged EU more homogenous.

Second, bringing CEECs into the EU comparisons shows that the range of values of NIC coefficients is higher within the current EU than within the CEECs, i.e. differences in innovation capacities within the current EU are larger than differences within the CEECs. The EU NIC coefficient ranges from 5.35 (Sweden) to -2.75 (Greece) while within CEECs the range is from -5.14 (Romania) to -0.11 (Estonia). In absolute terms, the EU range is 8.1 index points while for the CEEC this range is 5.03 index points. A large range in NICs within the EU countries explains why we find a more complex pattern of innovation capacities within the enlarged EU.

Third, the ranking of countries does not follow a simple 'East - West' divide but shows a more complex pattern. CEECs are not all grouped at the lower end of the spectrum, which would be followed by the Cohesion EU and then by the developed EU economies. Instead, South European countries (Greece, Portugal, Spain and Italy) are located within the CEE range of countries. NIC for Greece is below the CEE average. NICs of Spain and Italy are below the top three CEECs (Estonia, Czech R and Slovenia). In terms of income per capita, both Spain and even more so Italy are well ahead of these three CEECs. However, the NIC coefficient indicates the technological potential for catch-up, which may or may not be realized in the long-term. Figure 3 plots income per capita and NIC by country. Regressing NIC on income levels shows that NIC is a strong determinant of income per capita (Figure 3).

Figure 3

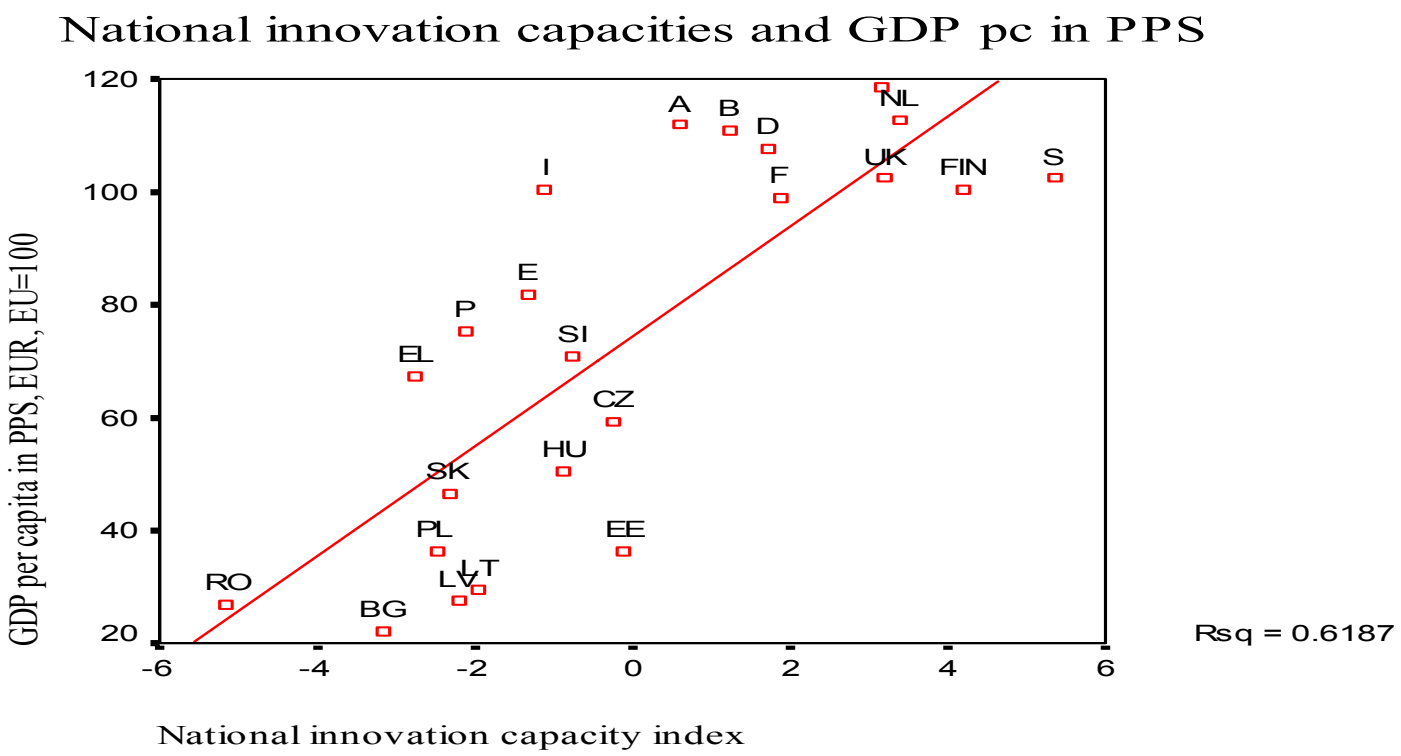


NIC explains $62 \%$ of the variation in income per capita and this impact is statistically significant.

\begin{tabular}{|c|c|c|}
\hline $\mathrm{GDP}_{1}$ & $74.58+$ & $9.76 \mathrm{NIC}$ \\
\hline $\mathrm{SE}$ & $(4.40)$ & (1.67) \\
\hline $\mathrm{t}$ & (16.94) & (5.84) \\
\hline Sig & 0.000 & 0.000 \\
\hline F-test & 34.07 & \\
\hline Sig & 0.000 & \\
\hline $\mathrm{R} 2=($ & & \\
\hline $\mathrm{R} 2 \mathrm{Ac}$ & 0.62 & \\
\hline
\end{tabular}

Figure 3 shows that most CEECs, except the richest (Slovenia) and the poorest (Romania) economies, have relatively higher NICs when compared to their income levels. In contrast, South EU economies (Portugal, Greece, Spain, Italy) have NIC indexes below what would be expected given their income levels. This suggests that the potential for catching up for the majority of CEECs to the income levels of South EU (Greece, Portugal, Spain) is significant. However, catching up to developed EU income levels would require significant improvements in national innovation capacities, i.e. it cannot be achieved based on the current levels of NIC. In the parlance of growth theory, this would suggest that the majority of CEECs have the potential for achieving membership of the South EU convergence club but not for catching up to the EU average. Figure 3 also suggests that we may see divergence within CEECs, in particular if the NICs for Romania and Bulgaria do not significantly improve.

Next we go on to analyze the different components of national innovation capacity.

\section{Absorptive capacities}

Table 2 and figure 4 rank countries according to the summary absorptive capacities index. The absorptive capacities index shows that Greece and Portugal are ranked very low on this scale - below the CEE average. Greece and Portugal have low ranking in most of the indicators of absorptive capacity, and in particular in employment in high tech industries and services as well as in share of science and engineering graduates compared to the CEE average. The high ranking of Estonia is due to high ranking on all six indicators of absorptive capacity. Also, Slovenia, Lithuania and Czech R rank high in this respect.

Italy ranks very low on this scale. Out of six variables Italy has a lower share than the CEE average in four: investments in education in GDP, share of science and engineering students in the population, share of population with $3^{\text {rd }}$ level education, and share of labour force undergoing training.

A high share of employment in medium-high-tech manufacturing in the case of the CEECs does not mean that these economies are involved in the high-tech segments of 
these industries. Figure 5 shows that very high shares of employment in medium-hightech are accompanied by very low share in GDP of business expenditure on R\&D. For example, Hungary and Sweden have similar shares of employment in medium-high-tech industries but R\&D intensity in the Hungarian business sector is eight times smaller in relative terms. Similarly, the share of employment in medium-high tech industries in Poland is the same as in Finland, Ireland and UK while Polish business R\&D (BERD) intensity is very low at only $0.25 \%$ of GDP. In Cohesion EU economies, Greece and Portugal relative shares of employment in medium-high tech industries in Greece and Portugal are 3 to 4 times lower than in the CEECs. It is important to bear in mind that the low shares of employment in medium-high-tech industries represents a problem for catching up, which is easier if the country is already involved in these sectors. In such cases, the pattern of catching-up is predominantly intra- rather than inter-sectoral. In this respect, the absorptive capacity of the majority of the CEECs is favourable. Figure 6 shows that if we exclude the most developed EU economies in terms of medium-hightech (Finland, Sweden, Denmark, the UK and the Netherlands) and the outlier Lithuania, there is positive relationship between the share of employment in medium-high tech sectors and the share of the labour force undergoing training. A high share of labour force in CEE being employed in medium-high-tech industries is an important determinant of the share of the labour force undergoing training irrespective of value added and R\&D in these sectors.

Figure 4: Absorptive capacities

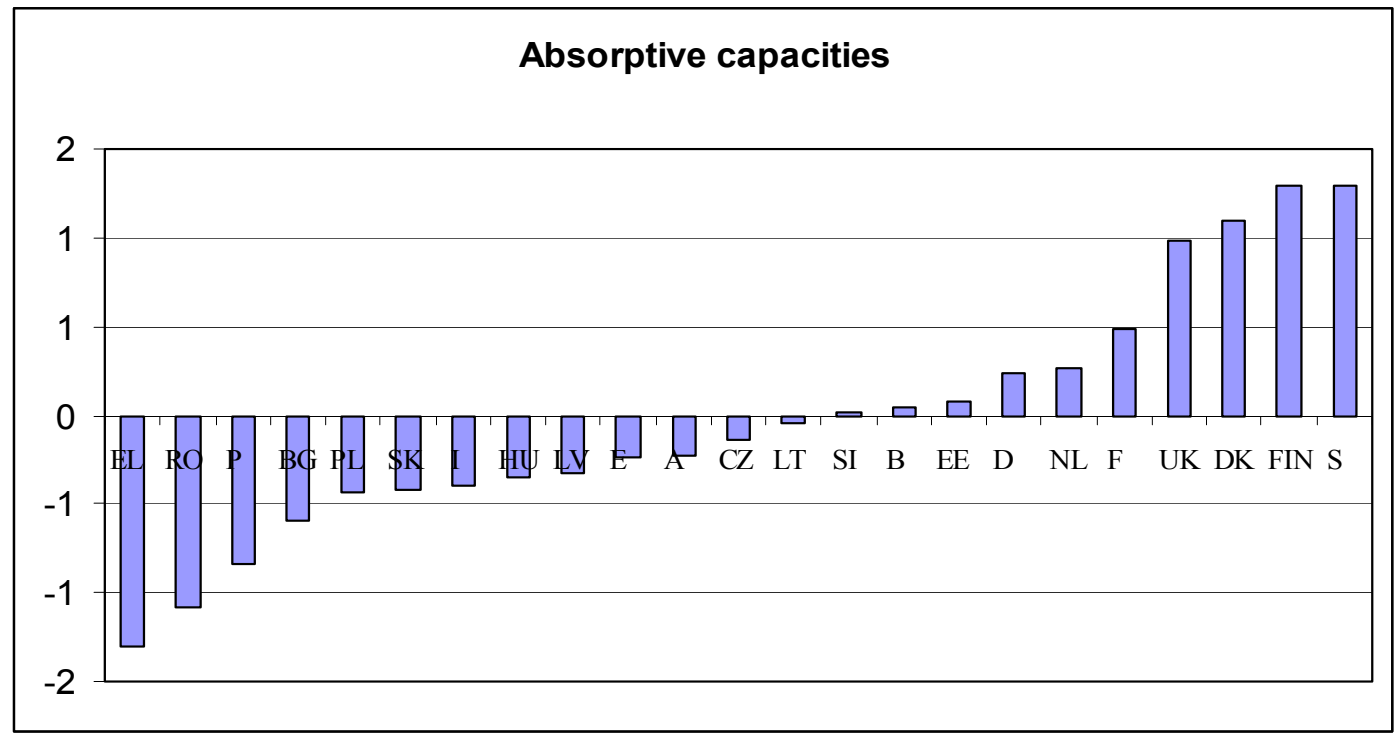


Figure 5: Employment in medium-high tech manufacturing vs. BERD/GDP

Employment in medium-high tech manufacturing vs BERD/GDP

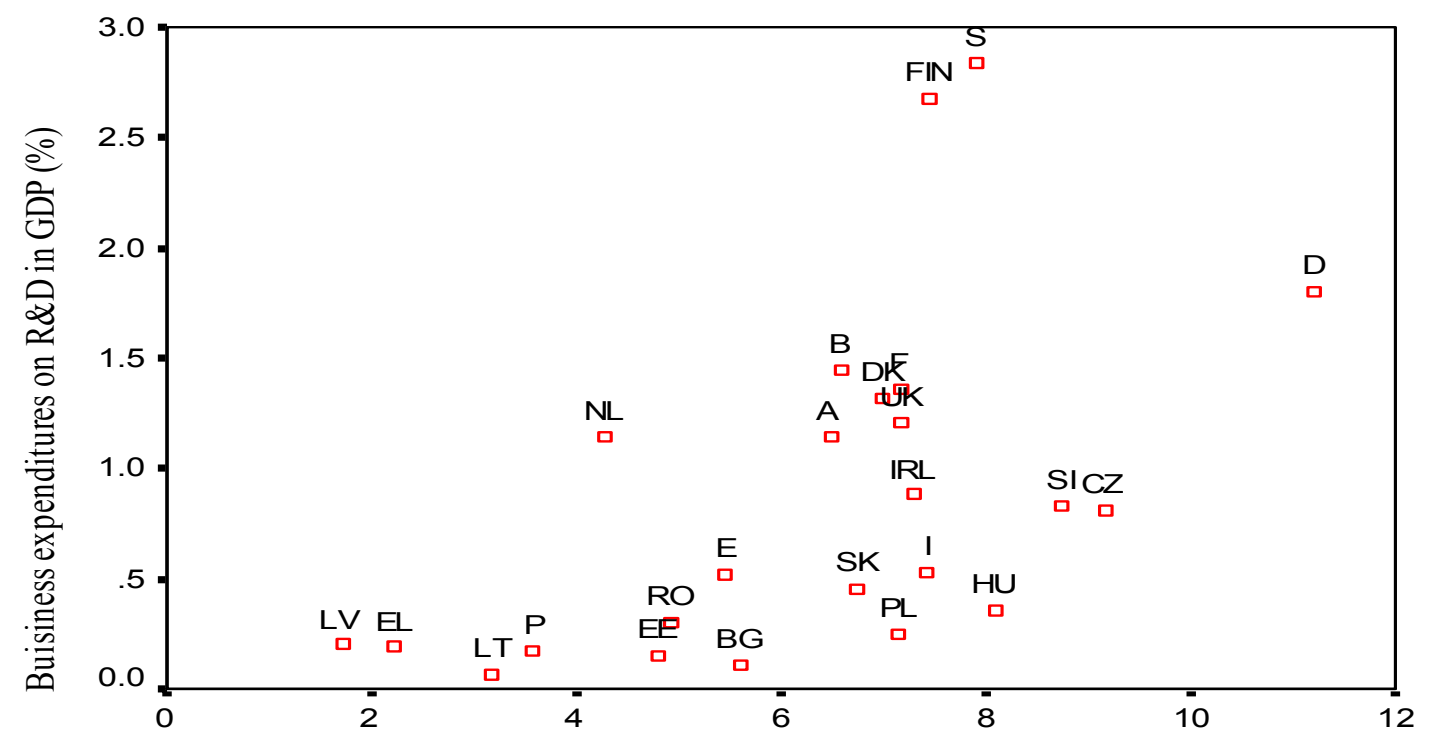

Employment in medium and high tech manufacturing (\%)

Figure 6: Relationship between \% employed in high tech industries and \% of labor force involved in training

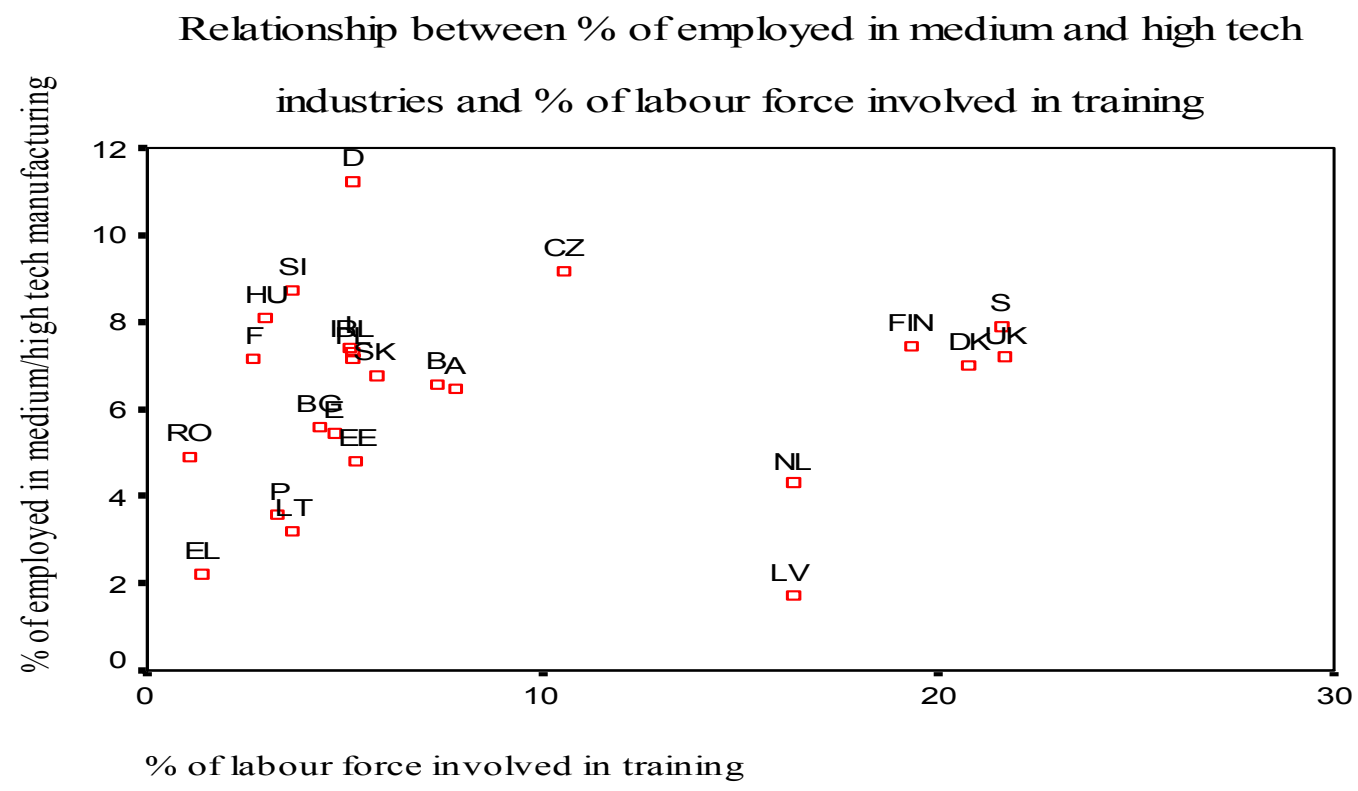




\section{$R \& D$ supply}

Unlike absorptive capacities, R\&D supply in CEECs is clearly at the low end of the EU ranking. There are five CEECs (Romania, Latvia, Slovakia, Poland, and Bulgaria), which rank behind Portugal, the least R\&D intensive EU economy. These countries are below the levels in the cohesion EU mainly due to the poor levels of investment (public and business R\&D and share of R\&D personnel in the labour force). After 10 years of decline in domestic R\&D, in most CEECs levels of relative investment are clearly behind those of the cohesion EU economies. Czech R and Slovenia are the only CEECs that managed to maintain relative levels of R\&D investment. This achievement, combined with a relatively high rate of resident patenting and relative number of researchers, puts these two economies in the range that is above the less developed EU economies.

\section{Figure 7: R\&D capacities}

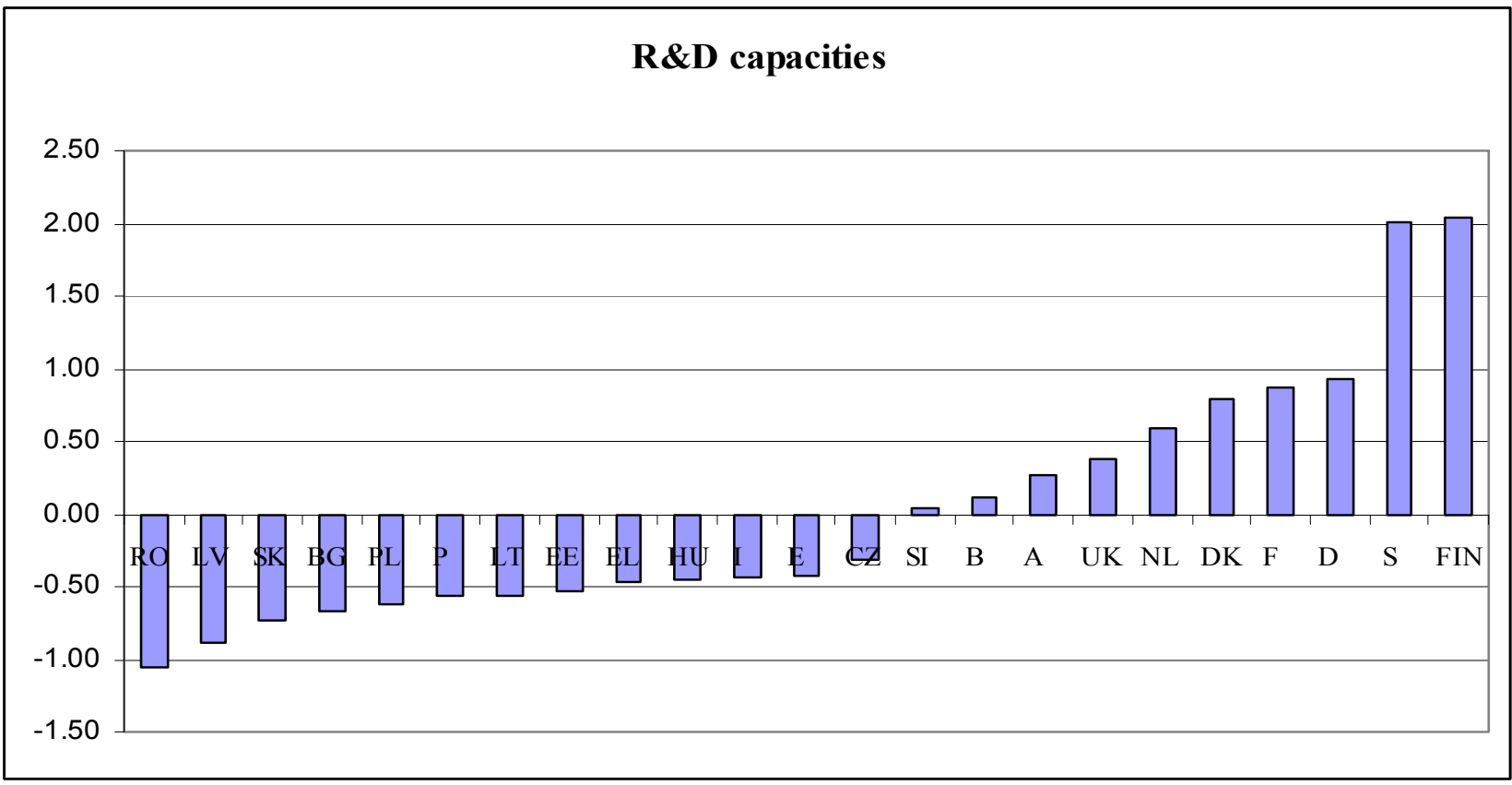

\section{Diffusion capacities}

Diffusion capacities in the CEECs are widely dispersed (Figure 8). Three CEECs (Romania, Bulgaria and Poland) are at the low end of the European ranking. The level of the CEECs is dispersed between the lowest of end of the enlarged EU to very high diffusion capacity of Czech $\mathrm{R}$, which is well above the EU average.

The share of the working age population that participates in lifelong learning is used to indicate absorptive capacity. Training enterprises as a percentage of all enterprises and share of costs of vocational training as a percentage of labour costs, together with the relative number of ISO9000 certificates are taken to approximate diffusion capacity. Diffusion currently is closely linked to IT and hence we also use Internet, PCs and share of ICTs in GDP as proxies for diffusion capacity. The very high ranking of Estonia and the Czech Republic is due to high rates of penetration of IT as 
well as the relatively extensive training and quality control activities (Czech R) and diffusion of Internet (Estonia). Romania, Bulgaria, Poland and partly Lithuania are behind in all these respects. For example, Lithuania, which has $45 \%$ of population with $3^{\text {rd }}$ level education, spends only $0.8 \%$ of labour costs on vocational training. Its absorptive capacity seems high but its low expenditure on training makes its diffusion capacity very weak. Slovenia, which ranks high in both R\&D and absorptive capacities, is relatively much weaker in terms of diffusion capacity.

Figure 8: Diffusion capacities

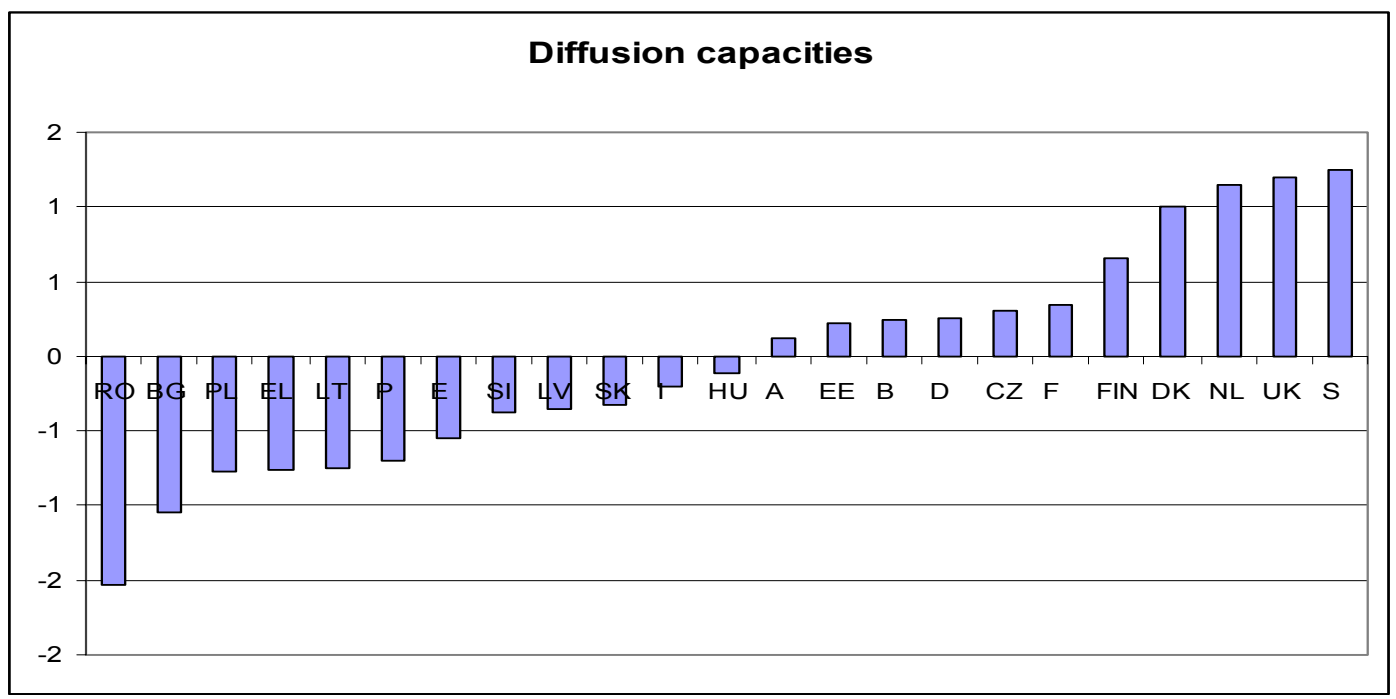

Capacity to generate demand for innovation

We assume that the capacity of an economy to generate demand for innovation is dependent, among other factors, on how well developed is its financial system, on the degree of competition and on the degree of macroeconomic stability. Figure 9 shows that the capacity to generate demand for innovation is the weakest aspect of the national innovation capacity of CEECs. Seven out of the ten CEECs clearly fall behind the cohesion EU economies in their capacity to generate demand for innovation. Estonia, Hungary and, to an extent, the Czech Republic, are distinctively different in this respect. In Estonia and Hungary, the reasons lie in their relatively developed stock markets and banking system and in high shares of FDI. Slovenia, which among CEECs ranks high in terms of absorptive capacity and particularly in terms of R\&D supply, is behind its central European peer. This is mainly due to its undeveloped financial system and low share of FDI.

This is the only dimension where one of the four advanced CEECs (Hungary, Czech R, Slovenia and Estonia) is behind the lowest ranked cohesion economy. In terms of absorptive, R\&D and diffusion capacity at least one of the four advanced CEECs is ahead of the lowest ranked cohesion economy. 
Figure 9: Demand capacities

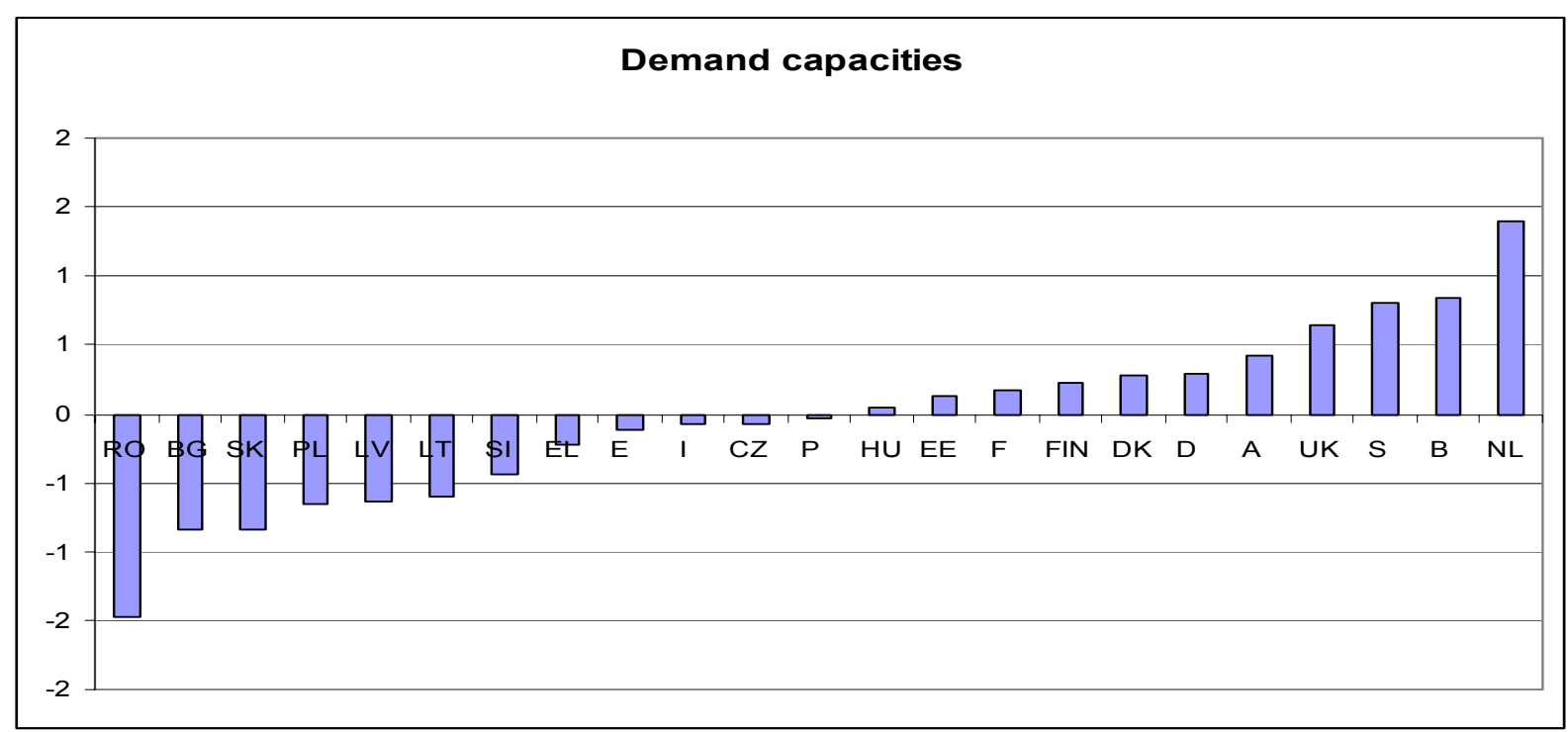

\subsection{National innovation capacity as determinant of productivity}

Figure 3 and the regression results presented in table 3 show that the high percentage of variation in income per capita can be explained by variations in NIC. In this section, we analyze the relationship between NIC and labour productivity in industry. Labour productivity is a far more direct measure of innovation, which shows the valueadded in purchasing power parities (PPS) which is being created by employees ${ }^{12}$.

Simple regressions for each of the components of NIC as explanatory variables are all highly significant with coefficients that are higher than coefficient for simple regression with the aggregate NIC. The most robust is the regression that explains labour productivity as the variation in capacity of demand for innovation. The weakest regression is labour productivity, which is explained through variation of absorptive capacity. Variation in demand capacity explains $63 \%$ and absorptive capacity only $32 \%$ of the variation in NIC.

When all four components of NIC are used to explain the levels of labour productivity across $\mathrm{CEE}$ and EU countries the overall regression is significant and adj. $\mathrm{R} 2$ is high (0.695) but three coefficients (absorption, $\mathrm{R} \& \mathrm{D}$ and diffusion) are either with the wrong sign or are insignificant. Only the demand component, when regressed jointly with other components, contributes significantly to explaining the variation in labour

\footnotetext{
${ }^{12}$ Income per capita of an economy can be influenced by rates of labour participation. The higher the unemployment rates, the greater the differences between GDP per capita and national productivity. Other factors, such as capital flows which include remittances and the age structure of the population, can also affect income levels.
} 
productivity. ${ }^{13}$ The ranking of the CEECs in table 2 shows that they are weakest in this dimension of NIC. Although individual components do not show the same variance in NIC, with the exception of demand, they cannot offer much by way of explanation of the variation when in mutual interaction. This suggests that NIC is not composed of 'ingredients' each simply accounting for different parts of the variation in NIC but that there is an interaction among the components that is more complex. The addition of individual components of NICs produces inconsistent regression results. Paradoxically, simple weighting and adding of individual variables better explains the variation in levels of labour productivity across countries than does adding individual components in regression.

Regression results suggest several interesting things. First, NIC as a conceptual framework has significant power in explaining variations in labour productivity. Second, results from the simple regression of individual components of labour productivity, which are better when compared to the results of multiple regressions, show the relevance of the national innovation system concept. Linear combinations of individual components do not produce NIC as its relationships are structured through nationally specific systems. Third, the explanatory power of demand capacity in both simple and multiple regressions, in which CEECs are relatively the weakest, has strong policy implications. However, our demand component contains both Keynesian (financial system, unemployment), and monetarist features (competition and price stability) that suggest that the right policy mix of supply and demand measures is crucial for improved innovation capacity.

\footnotetext{
${ }^{13}$ High eigenvalues and condition indexes below 5, average VIF of 3.3885 and tolerance value 0.3217 suggest that there is not strong multicollinearity among the four components of NIC.
} 
TABLE 3: Regression analysis of relationship between labour productivity in manufacturing and national innovation capacity and its components

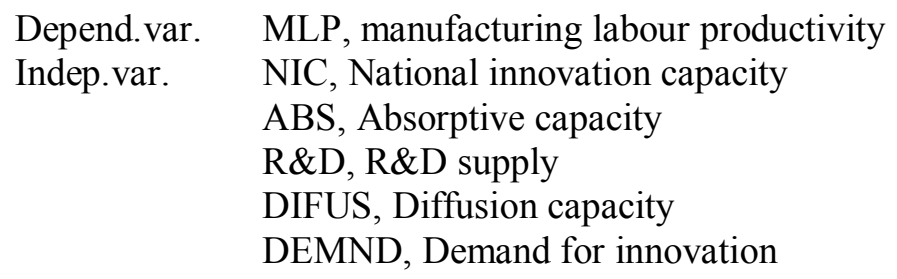

Number of observations: 22

\begin{tabular}{|c|c|c|c|c|c|c|c|c|c|c|}
\hline Variable & Constant & NIC & ABS & $\begin{array}{l}\text { R\& } \\
\text { D }\end{array}$ & DIFUS & $\begin{array}{l}\text { DEMN } \\
\text { D }\end{array}$ & R sq. & $\begin{array}{l}\text { Adj. R- } \\
\text { sq. }\end{array}$ & F-stat. & $\begin{array}{l}\text { Prob (F- } \\
\text { stat) }\end{array}$ \\
\hline Coefficient & 76.06 & 11.80 & & & & & 0.592 & 0.572 & 29.08 & 0.000 \\
\hline Std. Error & 5.70 & 2.188 & & & & & & & & \\
\hline t-stat & 13.34 & 5.392 & & & & & & & & \\
\hline Prob. & 0.000 & 0.000 & & & & & & & & \\
\hline Coefficient & 75.82 & & -0.237 & 25.3 & -24.71 & 51.75 & 0.753 & 0.695 & 12.96 & 0.000 \\
\hline Std. Error & 4.93 & & 20.82 & $\begin{array}{r}12.8 \\
2\end{array}$ & 22.58 & 17.96 & & & & \\
\hline t-stat & 15.131 & & -0.011 & 1.97 & -1.095 & 2.883 & & & & \\
\hline Prob. & 0.000 & & 0.991 & $\begin{array}{r}0.06 \\
5\end{array}$ & 0.289 & 0.010 & & & & \\
\hline Coefficient & 75.572 & & 34.585 & & & & 0.329 & 0.296 & 9.825 & 0.005 \\
\hline Std. Error & 7.325 & & 11.034 & & & & & & & \\
\hline t-stat & 10.350 & & 3.134 & & & & & & & \\
\hline Prob. & 0.000 & & 0.005 & & & & & & & \\
\hline Coefficient & 73.583 & & & $\begin{array}{r}34.4 \\
57\end{array}$ & & & 0.542 & 0.519 & 23.674 & 0.000 \\
\hline Std. Error & 6.019 & & & $\begin{array}{r}7.08 \\
2\end{array}$ & & & & & & \\
\hline t-stat & 12.226 & & & $\begin{array}{r}4.86 \\
6\end{array}$ & & & & & & \\
\hline Prob. & 0.000 & & & $\begin{array}{r}0.00 \\
0\end{array}$ & & & & & & \\
\hline Coefficient & 76.730 & & & & 38.780 & & 0.474 & 0.448 & 18.017 & 0.000 \\
\hline Std. Error & 6.500 & & & & 9.136 & & & & & \\
\hline t-stat & 11.806 & & & & 4.245 & & & & & \\
\hline Prob. & 0.000 & & & & 0.000 & & & & & \\
\hline Coefficient & 76.625 & & & & & 50.887 & 0.648 & 0.631 & 36.879 & 0.000 \\
\hline Std. Error & 5.301 & & & & & 8.379 & & & & \\
\hline t-stat & 14.454 & & & & & 6.073 & & & & \\
\hline Prob. & 0.000 & & & & & 0.000 & & & & \\
\hline
\end{tabular}




\subsection{Clustering of national innovation capacities in the wider Europe}

The ranking of CEE and EU countries based on NIC coefficients and their components shows that NIC in an enlarged EU do not follow a straightforward 'East West' division, but display a more complex pattern in which cohesion EU countries are often mixed in with the most developed CEECs. Cluster analysis enables us to examine more precisely how NICs in the enlarged EU are structured. This should improve our understanding of the catching up potential of individual candidate countries and of the cohesion issues in the enlarged EU.

Tables 4 - 8 show the results of cluster analysis of national innovation capacities of $10 \mathrm{CEE}$ and $14 \mathrm{EU}$ countries. We report the results of the hierarchical Ward method of clustering with agglomeration coefficients, which are used as criteria for determining the optimal number of clusters (stopping rule). ${ }^{14}$ We report cluster membership based on this method. However, as explained in the Data and Sources section we then use a nonhierarchical clustering method to define cluster membership for the number of clusters determined by the Ward method. Non-hierarchical clustering is used to fine-tune the cluster membership. In this way, comparing the results obtained from the two methods can check consistency of cluster membership. However, we take results of the nonhierarchical method as being final. We report the distances between final clusters in order to find out how close or far apart individual clusters are from one another. Table 4 shows the means for each variable within each final cluster and is useful to describe the attributes of each cluster. The last two columns in this table present the results of the Ftest and give us a rough idea of its statistical significance. ${ }^{15}$

Table 4 shows the results of clustering of national innovation capacities in the enlarged EU. We obtain three clusters of countries in the enlarged EU. Two clusters which comprised all CEE and cohesion EU have been 'fine tuned' into three clusters where EU high tech 'North' formed its owned cluster. Also, four central European countries form another cluster with the EU6.

\footnotetext{
${ }^{14}$ The agglomeration coefficient is the within cluster sum of squares. Small coefficients indicate that clusters are homogenous while a sudden jump indicates that two different clusters are merged. The rule is to take as the number of clusters the number before a significant jump in the agglomeration coefficient.

${ }^{15}$ The $\mathrm{F}$ test is the ratio between cluster variance and error variance. A large (significant) $F$ value indicates variables that are important for separating clusters while small (insignificant) values indicate variables that are not very useful for identifying cluster membership. However, because a non-hierarchical clustering algorithm is designed to minimize within-cluster variability, the $\mathrm{F}$ statistics cannot be interpreted in the same way as in a traditional ANOVA. This means that the significance values are not reliable estimates of the probability associated with the hypothesis of no effect for a particular variable. These values should be used only as guidelines.
} 
Table 4

Clustering of national innovation capacities

Hierachical Ward method

Number of Agglomeratio Percentage change in coeffcient to next level

clusters $n$ coefficient

$\begin{array}{lll}1 & 599.87 & \\ \mathbf{2} & \mathbf{3 5 9 . 6 6} & \mathbf{6 6 . 7 9 \%} \\ 3 & 299.99 & 19.89 \% \\ 4 & 261.68 & 14.64 \% \\ 5 & 231.14 & 13.21 \% \\ 6 & 201.33 & 14.81 \% \\ 7 & 174.74 & 15.22 \%\end{array}$

Cluster membership

Cluster 1 CEE10 + EU4 (EL, E, I, P)

Cluster 2 EU10

Non-hierarchical (K-means) clustering

Cluster 1 CEE6 + EU3 (BG, LT, LV, PL, RO, SK, + E, EL, P)

Cluster 2 EU3 FIN, S, DK

Cluster 3 EU6 + CEE4 (A, B, D, F, I, IRL + CZ, EE, HU, SL)

Distances between final clusters

$\begin{array}{rrrr} & 1 & 2 & 3 \\ 1 & & 10.073 & 4.947 \\ 2 & 10.073 & & 6.293 \\ 3 & 4.947 & 6.293 & \end{array}$

\begin{tabular}{lrrrrr} 
Final cluster centers & \multicolumn{6}{c}{ ANOVA } \\
& Cluster 1 & Cluster 2 & Cluster 3 & F & Sig. \\
eductgdp & -0.45 & 1.89 & -0.14 & 11.834 & 0 \\
segrdpop & -0.52 & 0.68 & 0.22 & 2.343 & $\mathbf{0 . 1 2 1}$ \\
pop3educ & -0.25 & 1 & -0.06 & 1.868 & $\mathbf{0 . 1 7 9}$ \\
llearng & -0.49 & 1.82 & -0.08 & 10.809 & 0.001 \\
emplhtec & -0.82 & 0.52 & 0.49 & 7.152 & 0.004 \\
emphsrvc & -0.99 & 1.45 & 0.38 & 24.63 & 0.000 \\
pubrd & -0.81 & 1.55 & 0.22 & 13.98 & 0.000 \\
besrd & -0.82 & 1.88 & 0.14 & 24.599 & 0.000 \\
rdpsnlab & -0.71 & 1.85 & 0.07 & 17.108 & 0.000 \\
epopc & -0.67 & 2.01 & 0 & 21.564 & 0.000 \\
usptopc & -0.72 & 2.2 & -0.01 & 41.846 & 0.000 \\
respat & -0.72 & 1.92 & 0.06 & 19.768 & 0.000 \\
trainent & -1 & 1.4 & 0.4 & 24.643 & 0.000 \\
cvtlabct & -0.89 & 1.66 & 0.25 & 21.718 & 0.000 \\
iso9kpc & -0.83 & 0.42 & 0.52 & 7.497 & 0.003 \\
internet & -0.89 & 1.65 & 0.25 & 21.306 & 0.000 \\
ppcpc & -0.93 & 1.63 & 0.28 & 23.94 & 0.000
\end{tabular}




$\begin{array}{lrrrrr}\text { ictgdp } & -0.69 & 0.7 & 0.34 & 4.403 & 0.025 \\ \text { stockmkt } & -0.45 & 1.29 & 0.01 & 4.189 & 0.029 \\ \text { domcredi } & -0.55 & -0.04 & 0.42 & 2.692 & \mathbf{0 . 0 9 1} \\ \text { fdigdp } & -0.41 & -0.13 & 0.34 & 1.43 & \mathbf{0 . 2 6 2} \\ \text { tradegdp } & -0.82 & 0.55 & 0.48 & 7.077 & 0.004 \\ \text { iprindex } & -0.89 & 0.46 & 0.55 & 9.68 & 0.001 \\ \text { unempl } & -0.68 & 0.54 & 0.38 & 4.17 & 0.030 \\ \text { cpi } & -0.4 & 0.36 & 0.21 & 1.168 & \mathbf{0 . 3 3 0}\end{array}$

The most surprising result of clustering NICs in an enlarged EU is (a) the splitting of advanced and less advanced CEECs into two groups and their grouping into two different EU groups, and (b) that the top three EU economies in terms of NIC are Finland, Sweden and Denmark, which form a separate cluster. Three EU cohesion economies (Spain, Portugal and Greece) with six of the less advanced EU economies (Slovakia, Romania, Latvia, Lithuania, Poland and Bulgaria) form a cluster. The distinguishing characteristic of this group is negative values on all 25 indicators that form NIC. ${ }^{16}$ The four advanced CEECs (Czech R, Slovenia, Estonia and Hungary) with the six EU economies, represent another separate cluster. When compared to the most advanced EU (cluster 2) and the least advanced group (cluster 1) this group has a mixed profile.

When cluster 1 (less advanced EU and CEE) is compared to cluster 3 (average EU and advanced CEE) the biggest advantages of the latter are in the dimensions of demand and diffusion while differences are much less distinct for R\&D and absorption factors. ${ }^{17}$ The average distance between the top EU group (cluster 2) and cluster 3 (average EU and top 4 CEECs) is bigger (6.293) than the distance between this latter group and cluster 1 (cohesion EU and less developed CEE group) (4.947). This shows that NICs within the current EU are quite polarized and that the enlargement of EU based on the four advanced CEECs will not lead to divergence but instead will make EU NICs more homogenous.

Clustering of the most developed CEECs with the average EU group shows that the former have significant potential for technological catch-up. The clustering of the less developed CEECs with the three EU cohesion economies says little about their technological potential and a great deal about the big gap in NIC between the cohesion EU and the EU average group (Austria, Belgium, Germany, France, Italy and Ireland).

It is interesting that neither share of FDI in GDP nor price stability significantly contribute to differentiation of countries in clusters. The high share of FDI in CEECs and the relative closeness of some EU economies to FDI, like Italy and Greece, explain this situation. Also, relatively low inflation in CEECs, whose economic policy strongly favours price stability, does not clearly differentiate the countries in the three groups.

Next we cluster separately each of the components of NICs.

\footnotetext{
${ }^{16}$ Unemployment and the price index have unchanged signs and hence positive values denote negative contributions to NIC.

${ }^{17}$ Two of six indicators of absorptive capacity (share of science and engineering students in the population and share of population with $3^{\text {rd }}$ level of education) do not contribute significantly to clustering which suggests that differences across the three groups in terms of absorptive capacity are also not clearly differentiated.
} 
Table 4 suggests that the clustering of absorptive capacity variables does not strongly differentiate CEE from EU countries. Table 5 shows that in terms of absorptive capacities enlarged EU is the least differentiated. In terms of absorptive capacities, six EU countries are more similar to the CEE than to the top EU7 (DK, F, FIN, IRL, NL, S, UK). Also, distances between these two clusters are the least among four components of NIC.

Table 5

Clustering of absorptive capacities

Hierachical Ward method

Number Agglomeration

Percentage change in coeffcient to

of clusters coefficient next level

$\begin{array}{lrr}1 & 143.96- & \\ \mathbf{2} & \mathbf{9 5 . 9 1} & \mathbf{5 0 . 1 0} \% \\ \mathbf{3} & 75.51 & 27.03 \% \\ 4 & 60.79 & 24.21 \% \\ 5 & 46.48 & 30.77 \% \\ 6 & 38.81 & 19.78 \% \\ 7 & 31.82 & 21.96 \%\end{array}$

Cluster membership

Cluster 1 CEE10 + EU8 (P, NL, I, EL, E, D, B, A)

Cluster 2 EU6 (F, FIN, IRL, S, UK, DK)

Non-hierarchical (K-means) clustering

Cluster 1 CEE10 + EU7

Cluster 2 EU7

(A, B, D, E, EL, I, P)

(DK, F, FIN, IRL, NL, S, UK)

Distances between final clusters

$\begin{array}{rrr} & 1 & 2 \\ 1 & & 3.167 \\ 2 & 3.167 & \end{array}$

Final cluster centers

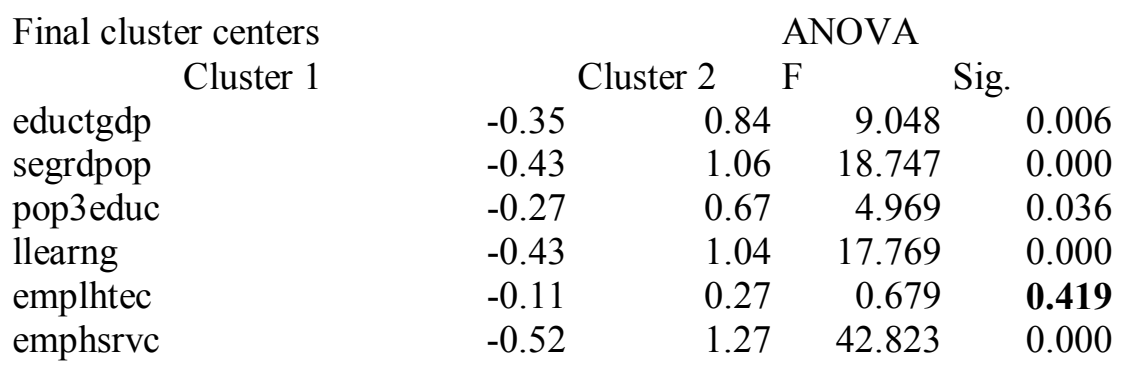


Netherlands is the only country that changed membership from hierarchical to nonhierarchical clustering. A joint clustering of the CEECs with the EU6 results from the combination of certain features of their absorptive capacity: either from high share of the population with $3^{\text {rd }}$ level education, high investment in education and/or high share of the workforce employed in high tech sectors.

Clustering based on six variables of absorptive capacity shows that only one of them (share of employment in medium and high tech sectors) does not contribute significantly to clustering.

The top EU7 economies in terms of absorptive capacities have positive values for all six variables while the first cluster shows negative values for all except share of employment in high tech sectors. We have already pointed out that the CEECs have a relatively high share of the workforce employed in low value added segments of high tech sectors. It is this 'unusual' structural feature of the CEE that produces insignificant coefficient for this variable in table 5 .

The clustering of R\&D variables in table 6 shows that the enlarged EU is the most polarized in terms of capacity for knowledge generation. It is the only component where hierarchal method has produced four clusters, which through fine-tuning are reduced to three clusters.

In terms of knowledge generation EU is split on EU 'North' (Sweden, Finland), EU 'South' (Spain, Italy, Greece and Portugal) and on EU 'Middle Earth' with Slovenia as the only CEE that is in this respect closer to the EU average than to the rest of the CEE. Distance of the EU medium group from the EU 'North' (4.883) is bigger than the distance to cluster 3 (CEE9 and EU cohesion) (2.817). All variables contribute significantly to cluster membership.

Table 6

Clustering of $R \& D$ supply capacities

Hierachical Ward method

Number Agglomeration Percentage change in coeffcient to next level of clusters coefficient

$\begin{array}{lrr}1 & 144.05 & \\ 2 & 68.85 & 109.24 \% \\ 3 & 26.83 & 156.61 \% \\ \mathbf{4} & \mathbf{1 9 . 0 7} & \mathbf{4 0 . 7 0 \%} \\ 5 & 14.20 & 34.30 \% \\ 6 & 11.70 & 21.35 \% \\ 7 & 9.53 & 22.77 \%\end{array}$

Cluster membership

Cluster 1 CEE9 + EU4 (CEEC + E, EL, I, P) $)$

(I, E, P, EL)

Cluster 2 EU4 + CEE1 (A, B, IRL, UK) + SI 


\begin{tabular}{|c|c|c|c|}
\hline Cluster 3 & EU4 & \multicolumn{2}{|c|}{$(\mathrm{D}, \mathrm{DK}, \mathrm{F}, \mathrm{NL})$} \\
\hline Cluster 4 & EU2 & \multicolumn{2}{|c|}{$(\mathrm{FIN}, \mathrm{S})$} \\
\hline \multicolumn{4}{|c|}{$\begin{array}{l}\text { Non-hierarchical (K-means) } \\
\text { clustering }\end{array}$} \\
\hline Cluster 1 & EU 2 & \multicolumn{2}{|c|}{$(\mathrm{S}, \mathrm{FIN})$} \\
\hline Cluster 2 & EU7 + CEE1 & \\
\hline Cluster 3 & CEE9 + EU5 & \multicolumn{2}{|c|}{$\begin{array}{l}(\mathrm{UK}, \mathrm{F}, \mathrm{NL}, \mathrm{DK}, \mathrm{D}, \mathrm{B}, \mathrm{A})+\mathrm{SI} \\
(\mathrm{CEEC}+\mathrm{E}, \mathrm{EL}, \mathrm{I}, \mathrm{P}, \mathrm{IRL})\end{array}$} \\
\hline \multicolumn{4}{|c|}{ Distances between Final Cluster Centers } \\
\hline & & 2 & 3 \\
\hline & & 4.883 & 7.56 \\
\hline 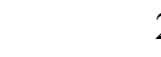 & 4.88 & & 2.817 \\
\hline 3 & 7.5 & 2.817 & \\
\hline
\end{tabular}

Final cluster centers

ANOVA

\begin{tabular}{|c|c|c|c|c|c|}
\hline & Cluster 1 & Cluster 2 & Cluster 3 & $\mathrm{~F}$ & Sig. \\
\hline pubrd & 1.89 & 0.69 & -0.67 & 26.255 & 0.00 \\
\hline besrd & 2.52 & 0.55 & -0.68 & 91.424 & 0.00 \\
\hline rdpsnlab & 2.18 & 0.58 & -0.64 & 30.987 & 0.00 \\
\hline epopc & 2.89 & 0.23 & -0.54 & 80.265 & 0.00 \\
\hline usptopc & 2.78 & 0.42 & -0.64 & 151.234 & 0.00 \\
\hline respat & 2.38 & 0.53 & -0.64 & 43.262 & 0.00 \\
\hline
\end{tabular}

Table 4 shows that differences in diffusion capacities between the less developed CEECs and the three cohesion EU economies (cluster 1) and the top EU3 (Finland, Sweden and Denmark) (cluster 2) are consistent with opposite signs and values. The intermediate cluster group 3 (the four advanced CEECs and the 6 average EU) all have positive signs in terms of diffusion capacity but with exception of ISO9090 certificates the values of all variables are lower than in the top EU group.

Final, non-hierarchical clustering of only diffusion capacities (table 7) distinguishes two groups of countries. CEECs are again split into two groups, advanced and less advanced CEECs; while the EU countries are also split into 2 clusters. This split is caused by on one side cohesion EU (Spain, Greece, Portugal and Italy) and on the other by developed diffusion capacities of Estonia and Czech Republic. 
Table 7

Clustering of diffusion capacities

Hierachical Ward method

Number Agglomeratio Percentage change in coeffcient to next level of clusters $n$ coefficient

$\begin{array}{rrr}1 & 143.98 & \\ 2 & 69.24 & 107.94 \% \\ \mathbf{3} & \mathbf{5 0 . 2 9} & \mathbf{3 7 . 6 9 \%} \\ 4 & 41.36 & 21.57 \% \\ 5 & 32.94 & 25.57 \% \\ 6 & 25.57 & 28.85 \% \\ 7 & 19.37 & 32.01 \%\end{array}$

Cluster membership

Cluster 1 CEE8 + EU4 (BG, LT, PL, RO + EL, E, I, P)

Cluster 2 EU4 + CEE2 (F, A, B, D + EE,

Cluster 3 EU $6 \quad$ (DK, FIN, IRL, S, NL, UK)

Non-hierarchical (K-means) clustering

Cluster 1 CEE8 + EU4 (All CEECs except CZ and EE + EL, E, P, I)

Cluster 2 EU10 $+\quad(E U 10+\mathrm{CZ}, \mathrm{EE})$

CEE2

Distances between Final Cluster Centers

Cluster

12

$1 \quad 3.529$

$2 \quad 3.529$

Final cluster centers

Cluster 1

Trainent

Cvtlabct

ANOVA

iso9 $\mathrm{kpc}$

\begin{tabular}{|c|c|c|}
\hline \multicolumn{3}{|c|}{ ANOVA } \\
\hline Cluster 2 & & \\
\hline 0.88 & 76.994 & 0.000 \\
\hline 0.78 & 34.085 & 0.000 \\
\hline 0.6 & 12.264 & 0.002 \\
\hline 0.67 & 18.326 & 0.000 \\
\hline 0.77 & 32.157 & 0.000 \\
\hline 0.57 & 10.505 & 0.004 \\
\hline
\end{tabular}

The distance between cluster centers of the two groups are relatively small and are similar to distances for absorptive capacities. All variables significantly contribute to clustering. 
Initially, a hierarchical clustering of capacities for generating demand for innovation is the one that clearly separates the CEECs from the EU economies (table 8). Fine-tuning of the 3-cluster solution via non-hierarchical clustering shows Romania to be significantly different from the rest of the CEE. Undeveloped stock market, but low share of domestic credit and high inflation can explain much of this distinctive position of Romania.

Fine-tuning of the initial three-cluster solution has kept all the CEE, except Romania, together. In terms of diffusion capacities the CEECs seems to be the most homogenous.

However, the most surprising is clustering of Finland in a group with the CEEC and the cohesion EU. High share of stock market, low share of domestic credit but also low share of FDI makes position of Finland in terms of demand capacity closer to the cohesion EU than to the rest of the EU. However, distance between this group and the rest of the EU is relatively small.

Table 8

Clustering of demand for innovation

Hierachical Ward method

Number Agglomeration Percentage change in coefficient to next

of clusters coefficient level

$\begin{array}{lrr}1 & 167.88- & \\ 2 & 122.48 & 37.06 \% \\ \mathbf{3} & \mathbf{1 0 0 . 3 2} & \mathbf{2 2 . 1 0 \%} \\ 4 & 80.15 & 25.16 \% \\ 5 & 65.87 & 21.67 \% \\ 6 & 54.23 & 21.48 \% \\ 7 & 46.50 & 16.62 \%\end{array}$

Cluster membership

Cluster 1 CEE10

All

CEECs

Cluster 2 EU9 (A, D, DK, E, EL, F, FIN, I, P)

Cluster 3 EU5 (B, IRL, NL, S, UK)

Non-hierarchical (K-means)

clustering

Cluster 1 RO

Cluster 2 EU8 (A, B, D, DK, IRL, NL, S, UK)

Cluster 3 CEE9 + CEE6 (All CEE except RO + E, EL, F, FIN, I, P)

Distances between Final Cluster Centers

1

12

$6.534 \quad 4.98$ 


$\begin{array}{lrll}2 & 6.534 & & 2.752 \\ 3 & 4.98 & 2.752 & \end{array}$

\begin{tabular}{lrrrrr} 
Final cluster centers & \multicolumn{5}{c}{ ANOVA } \\
& Cluster 1 & \multicolumn{5}{c}{ Cluster 2 } & Cluster 3 & F test & Sig. \\
stockmkt & -0.95 & 0.42 & -0.16 & 1.351 & $\mathbf{0 . 2 8 1}$ \\
domcredi & -1.44 & 0.89 & -0.38 & 8.324 & 0.002 \\
fdigdp & -0.68 & 0.4 & -0.17 & 1.05 & $\mathbf{0 . 3 6 8}$ \\
tradegdp & -1.33 & 1.02 & -0.46 & 12.791 & 0.000 \\
iprindex & -0.84 & 0.76 & -0.35 & 4.533 & 0.023 \\
unempl & -0.47 & 0.9 & -0.45 & 7.071 & 0.004 \\
cpi & -4.56 & 0.37 & 0.11 & 117.67 & 0.000
\end{tabular}

Individual variables have expected signs and values. However, FDI and stock market variables do not contribute significantly to clustering in three groups. When compared to the CEECs, the average value of FDI for the EU12 is below the average for the CEECs. A great openness of CEEC to FDI has made them extremely dependent on foreign capital and technology which has produced marked effects on market competition and market structure. A high share of FDI inflows does not necessarily correlate with high NIC which justifies our interpretation of FDI as a proxy for competition rather than for technology or capital inflow. However, as might be expected, the effects of FDI on competition can be ambiguous because of the domestic vs. export orientation of FDI.

In summary, clustering of capacities for demand for innovation shows that in this respect CEECs are the most homogenous. This may not be so much problem for the less developed CEE but is probably for the advanced CEECs which have been significantly ahead of the other CEECs on other three dimension of NIC. Although demand conditions for innovation are unfavourable across the entire region, even in this respect EU cohesion economies are more similar to the CEE than to the rest of the EU.

\section{CONCLUSIONS}

1. National innovation capacity provides a robust conceptual framework for understanding the factors that determine productivity and technical change. This intermediate line in the research falls between the overly aggregate approaches of new and neo-classical growth theory, on one hand, and case study and exclusively micro approaches, on the other. By using a large number of indicators from a system of innovation framework perspective the NIC framework shows the multidimensional nature of innovation capacity while keeping the analysis at the macro level. Following the national innovation system approach we organized the indicators into four groups ( $R \& D$ supply, absorptive capacity, diffusion and demand). What underpins this grouping is the assumption that growth and innovation capacity of an economy depends not only on the supply of R\&D but also on the capability to absorb and diffuse technology and demand for its generation and utilization. 
2. NIC as conceptual framework has significant power to explain the variations in labour productivity. Individual components of NIC also have significant explanatory power for labour productivity. However, the poor regression results obtained when individual components are grouped point to the relevance of national systems of innovation for understanding how different dimensions of NIC interact.

3. When CEECs are included in the current EU they shift the index of NIC downwards. However, the range of values of NIC coefficients is higher within the current EU than within the CEECs. A wide range of NICs across the EU explains why we will find a more complex pattern of innovation capacities within the enlarged EU. The ranking of countries does not follow a simple 'East - West' divide. In terms of NICs, the wider Europe is structured into three groups of which CEECs are split across two, the less developed and medium developed EU groups. The less advanced CEECs have NICs that cluster them with the cohesion EU while the four advanced CEECs are similar to the medium EU group. Clustering of capacity for demand for innovation shows CEECs to be the most homogenous group but also the weakest. Demand conditions for innovation are unfavourable across the entire region. South European countries (Greece, Portugal, Spain and Italy) are located within the CEE range of countries. This ranking raises interesting issues regarding the differences between income per capita levels and NICs and raises interesting issues regarding the potential for catching up by the advanced CEECs to the income levels of the cohesion EU.

4. What distinguishes the advanced from the less advanced CEECs is better capacity of the advanced CEECs in absorptive and R\&D capabilities; in terms of diffusion, and particularly demand capacities, differences are smaller. The potential for catch-up to the levels of income of the cohesion EU is very high for the four highest level CEECs in terms of NIC (Estonia, Slovenia, Czech R and Hungary). Clustering analysis shows that in terms of NIC the four advanced CEECs are actually more similar to the 'average EU' group than to the cohesion EU group. Relatively advanced absorptive and diffusion capacities, of advanced CEECs, and poor levels (except in Slovenia) of R\&D capacity, seem to be decisive for their clustering close to medium level EU countries in terms of NIC. The NICs of the less advanced CEECs are more similar to those of the cohesion EU than those of the cohesion EU countries are to the medium and developed EU. However, in terms of levels of individual indicators most of the less advanced CEECs are behind the cohesion EU.

5. CEECs are relatively well placed within the wider Europe in terms of absorptive capacity, which is the combined result of education and training indicators and high share of employment in high tech sectors. If we take similarity to EU NICs as the main criterion than the policy priorities for the CEE in order of priority would be: demand, R\&D and diffusion. However, analysis shows that only nationally specific policy implications can be analytically based. Points of departure for national policies are discrepancies in the strength of individual dimensions of NICs. For example, Slovenia is relatively much better in terms of $R \& D$ and absorptive capacities than in diffusion and demand capacities. Estonia is the only CEEC with positive coefficients for both demand and diffusion. Although it is weak in R\&D, Estonia has the best potential for catching up if we take NIC as the criterion.

6. From a policy perspective the NIC framework suggests that innovation is a multidimensional and multilevel activity. The policy focus should be on all four 
dimensions. For example, it would be undesirable to focus on absorption to the extent that overall $R \& D$ stock is reduced. Countries that spend more on $R \& D$ are able to take greater advantage of foreign technology. Our analysis suggests that the CEECs' absorptive capacities are relatively better than their current R\&D capacities which, after 10 years of weak demand, have become a bottleneck in the bid to improve NIC. Countries that are further behind the technology frontier have more to gain from increasing their R\&D efforts since these efforts are more likely to allow them to capture international spillovers from technologically advanced countries. In the context of CEE, this would mean that strengthening of weak R\&D should be given much more priority by policy makers in these countries than is currently the case. However, weak demand for innovation is the key obstacle to increased R\&D: thus the situation cannot be rectified by increasing public R\&D spending without there being increased demand for innovation from the business sector.

\section{REFERENCES:}

Aghion, P. and P. Howit (1998) Endogenous Growth Theory, Cambridge MA: The MIT Press.

Campos, F. N. (2000), 'Context is everything: Measuring Institutional Change in Transition Economics', World Bank Policy Research Working Paper No. 2269, January, Washington D.C.: World Bank..

Campos, N. F. and F. Coricelli (2002) 'Growth in transition: what we know, what we don't and what we should', Journal of Economic Literature, Vol. XL (September): 793836.

Carlin, W, S. Fries, M. Schaffer and P. Seabright (2001) 'Competition and enterprise performance in transition economics : evidence from cross-country survey', $E B R D$ Working Paper, No. 63, June, London: European Bank for Reconstruction and Development.

CEC (2000), 'Benchmarking Enterprise Policy, First results from the Scoreboard', Commission Staff Working Document, SEC (2000)1842, Brussels: Commission of the European Communities.

Cohen, W. M. and D. Levinthal, (1989) 'Innovation and Learning: The Two Faces of R\&D’, Economic Journal, Vol. 99(397)): 569-96.

Cohen, W. M. and D. Levinthal, (1990), 'Absorptive Capacity: A new perspective on learning and innovation', Administration Science Quarterly, Vol. 35 (1): 128-152.

Davies, S. W. (1979), The Diffusion of Process Innovations, Cambridge: Cambridge University Press. 
De Broeck, M. and V. Koen (2000), 'The great contractions in Russia, the Baltics and the other countries of the former Soviet Union: A view from the supply side', IMF Working Paper, (January), Washington: IMF.

Dyker, D. and S. Radosevic (1999) 'What quantitative analysis of trends in science and technology tell us about patterns of transformation and growth in the post-socialist countries?' In Dyker. D. and S. Radosevic, (eds.) Innovation and Structural Change in Post-Socialism, NATO Science Series, Dordrecht: Kluwer Academic Publishers, pp. 128.

Easterly, W. (2002), The Elusive Quest for Growth. Economists'Adventures and Misadventures in the Tropics, Cambridge, MA: The MIT Press.

Edquist, C. (Ed.) (1997) Systems of Innovation: Technologies, Institutions and Organizations, London: Pinter Publishers.

EC (2001) Trendchart Innovation Scoreboard 2001, Luxembourg: European Commission.

EC (2002a), European Innovation Scoreboard 2002, Cordis Focus, Issue No, 19, December, Luxembourg: European Commission.

EC (2002b), Report on Research and Development, Economic Policy Committee, Working Group on R\&D, EPC/ECFIN/01/777-EN, January 10, Brussels: European Commission.

Freeman, C. and L. Soete (1997), The Economics of Industrial Innovation, Third Edition, London: Pinter.

Ginarte, J. C. and W. G. Park (1997) 'Determinants of patent rights: A cross-national study’, Research Policy Vol. 26: 283-301.

Grilliches, Z. (1997), R\&D and Productivity Slowdown: Is Recovery around the corner, mimeo, In OECD (2002)

Hair, J. H., R. E. Anderson, R. T. Tatham and W. C. Black (1998) Multivariate data analysis, Fifth Edition, London: Prentice Hall International.

Haltiwanger, J. C. (1997), 'Measuring and Analyzing Aggregate Fluctuations: The Importance of Building from Microeconomic Evidence', Federal Reserve Bank of St Louis Review, May/June:55-77.

Haltiwanger, J. (2000), 'Aggregate Growth: What have we learned from Microeconomic Evidence?', OECD Economics Department Working papers No. 276, Paris: OECD. 
Lundvall, B.-A. (Ed.) (1992), National Systems of Innovation--Towards a Theory of Innovation and Interactive Learning, London: Pinter Publishers.

Nelson, R. (Ed.) (1993), National Systems of Innovation: A Comparative Study, New York: Oxford University Press.

OECD (2002), OECD Productivity Manual, Paris: OECD.

OECD (2002b) Dynamising National Innovation Systems, Paris: OECD.

Perez, C. (2002), Technological Revolutions and Financial Capital: The Dynamics of Bubbles and Golden Ages, Cheltenham, UK and Northampton, MA: Edward Elgar Publishing.

Porter, M. E. (1990) The Competitive Advantage of Nations. New York: Free Press.

Porter, M. E., J. D. Sachs, P. K. Cornelius, J. W. McArthur and K. Schwab (2002) World Competitiveness Report 2001-2002, New York: Oxford University Press.

Radosevic, S. and L. Auriol (1999), 'Patterns of Restructuring in Research, Development and Innovation Activities in Central and Eastern European Countries: Analysis Based on S\&T Indicators', Research Policy, Vol. 28: 351-376.

Sanghoon, A. and P. Hemmings (2000), Policy influences on economic growth in OECD countries: An evaluation of the evidence, Economics Department Working Paper No. 246, Paris: OECD.

Scarpeta, S., A. Bassaninini, D. Pilat and P. Schreyer (2000), 'Economic growth in the OECD area: Recent trends at the aggregate and sectoral level', Economic Department Working Papers No. 248, ECO/WKP (2000)21, Paris: OECD.

Smarzynska, K. B. (2002), 'Composition of foreign direct investments and protection of intellectual property rights in economies in transition', World Bank Working Paper, No. 2786, February 15, Washington: The World Bank.

Stephan, J. (2002), 'The Productivity gap between East and West Europe: What Role for Sectoral Structures during Integration?', Acta Oeconomica, Vol. 52(3): 289-305

UNDP (2002), Human Development Report 2002: Deepening Democracy in a Fragmented World, New York: Oxford University Press.

UNIDO (2002), Industrial Development Report 2002/2003: Competing through innovation and learning, Vienna: United Nations Industrial Development Organization.

Verspagen, B. (2001), 'Economic growth and technological change: an evolutionary interpretation', STI Working Papers 2001/1, OECD, Paris. 
von Tunzelmann, N. (1995), 'Technology and Industrial Progress. Foundations of Economic Growth', London: Edward Elgar.

Zinnes, C., Y. Eilat and J. Sachs (2001), 'Benchmarking competitiveness in transition economies', Economics of Transition, Vol. 9(2): 315-353. 